ISSN 0103-9954

\title{
AVALIAÇÃO DA REGENERAÇÃO NATURAL EM NASCENTES PERTURBADAS NO MUNICÍPIO DE LAVRAS, MG
}

\author{
EVALUATION OF NATURAL REGENERATION IN DISTURBED SPRINGS IN LAVRAS, MG
}

\author{
Marciel José Ferreira ${ }^{1} \quad$ Israel Marinho Pereira $^{2} \quad$ Soraya Alvarenga Botelho $^{3} \quad$ Carlos Rogério de Mello $^{4}$

\section{RESUMO}

Este trabalho teve como objetivo avaliar a dinâmica da regeneração natural em duas nascentes em processo de recuperação no município de Lavras, MG. Para tanto, foram realizados dois inventários após o isolamento das áreas, nos períodos de Agosto/2005 (18 meses) e Abril/2006 (24 meses). Foram alocadas no total 122 parcelas de $5 \times 5 \mathrm{~m}\left(25 \mathrm{~m}^{2}\right)$, sendo 76 na nascente 1 e 46 parcelas na nascente 2 . As parcelas foram distribuídas de forma sistemática ao longo de toda a área das nascentes. Todos os indivíduos com altura superior a $0,10 \mathrm{~m}$ e DAP (diâmetro a altura do peito) $<5 \mathrm{~cm}$, foram identificados, tendo seus diâmetros e alturas mensuradas. Foram avaliadas a composição florística, a estrutura, e a dinâmica da regeneração natural. Foram amostrados no total 524 indivíduos pertencentes a 24 famílias e 55 espécies. A família Asteraceae se destacou em número de espécies na nascente 1 e as famílias Fabaceae Faboideae, Myrtaceae e Solanaceae na nascente 2. As espécies Baccharis dracunculifolia e Vernonia ferruginea apresentaram os maiores índices de regeneração natural, na nascente 1, enquanto que as espécies Vernonia polyanthes e Nectandra nitidula se destacaram na nascente 2. O maior índice de diversidade foi registrado para a nascente 2 na segunda avaliação, aumentando de 3,324 (primeira avaliação) para 3,384 (segunda avaliação). O índice de similaridade florística encontrado entre as duas nascentes, foi de 20,0 e $18,5 \%$ para as avaliações 1 e 2 respectivamente. Durante o período de monitoramento, verificou-se um aumento significativo de 33,33 e 15,8\% no número de indivíduos amostrados nas nascentes 1 e 2 respectivamente. O método da regeneração natural apresenta grande potencial para a recuperação da vegetação no entorno das duas nascentes, sendo necessária, no entanto, a adoção de técnicas de controle do capim Brachiaria sp.

Palavras-chave: espécies florestais nativas; análise florística; análise estrutural; dinâmica.

\section{ABSTRACT}

This work aimed at evaluating the natural regeneration dynamics in two springs in process of recovery in Lavras-MG, surrounded in December/2003. To do that, two springs were carried out from August/2005 (18 months) to April/2006 (24 months). 122 plots in the total of 5 x $5 \mathrm{~m}\left(25 \mathrm{~m}^{2}\right)$ were plotted, being 76 plots in spring 1 and 46 plots in spring 2 . The plots were distributed systematically throughout all the area of the springs. All individuals with height larger than $0.10 \mathrm{~m}$ and DBH lower than $5 \mathrm{~cm}$ were identified, having their diameters and height measured. Floristic composition, structural analyses and natural regeneration dynamics were studied. In the total, 524 individuals from 24 family and 55 species were sampled. The Asteraceae family was distinguished in species number in spring 1 and the families Fabaceae Faboideae, Myrtaceae and Solanaceae in spring 2. The species Baccharis dracunculifolia and Vernonia ferruginea presented the highest natural regeneration indexes in spring 1, while the species Vernonia polyanthes and Nectandra nitidula in spring 2. The higher diversity index was registered for the spring 2 in the second evaluation, having an increase from 3,324 (first evaluation) to 3,384 (second evaluation). The floristic similarity index registered between the springs was of $20.0 \%$ and $18.5 \%$ for the evaluations 1 and 2 , respectively. During the time of monitoring, it was verified a significant increase of $33.33 \%$ and $15.8 \%$ in individuals number sampled in springs 1 and 2, respectively. The natural regeneration method presents potential for the recovering of the vegetation of the two springs; however, it is necessary the adoption of

1. Engenheiro Florestal, Doutorado em Ciências de Florestas Tropicais, Instituto Nacional de Pesquisas da Amazônia, Caixa Postal 478, CEP 69011-970, Manaus (AM). ferreiraufla@yahoo.com.br

2. Engenheiro Florestal, Dr., Professor do Departamento de Engenharia Florestal, Universidade Federal do Vale do Jequitinhonha e Mucuri, CEP 39100-000, Diamantina (MG). imarinhopereira@gmail.com

3. Engenheira Florestal, Dr ${ }^{\mathrm{a}}$., Professora do Departamento de Ciências Florestais, Universidade Federal de Lavras, Caixa Postal, 37, CEP 37200, Lavras (MG). sbotelho@ufla.br

4. Engenheiro Agrícola, Dr., Professor do Departamento de Engenharia Agrícola, Universidade Federal de Lavras, Caixa Postal, 37, CEP 37200, Lavras (MG). crmello@ufla.br

Recebido para publicação em 11/10/2007 e aceito em 23/04/2009. 
control techniques of Brachiaria sp. grass.

Keywords: native forest species; floristic analysis; structural analysis; dynamic.

\section{INTRODUÇÃO}

As matas ciliares, que são formações florestais que ocorrem ao longo de cursos d'água e no entorno de nascentes, são fundamentais na manutenção da quantidade e qualidade da água de um reservatório, sendo responsáveis pelo aumento da infiltração de água no solo, redução do processo erosivo, contenção de barrancos, dentre outras vantagens (LIMA, 1989; DAVIDE e BOTELHO, 1999; CARVALHO, 2000; BOTELHO e DAVIDE, 2002).

No entanto, apesar desse ecossistema desempenhar importantes funções, contribuindo com a qualidade dos recursos hídricos, o mesmo tem sofrido constantes agressões, seja pela expansão agrícola, pelo crescimento demográfico desordenado, ou ainda pela criação de usinas hidrelétricas, reduzindo sobremaneira sua extensão vegetacional. Nesse contexto, torna-se necessária a adoção de ações que visem a promover a recomposição da vegetação destes ambientes, e com isso garantir a manutenção da qualidade dos recursos hídricos de uma bacia hidrográfica.

O estudo da regeneração natural de espécies arbóreas e arbustivas nativas ocorrentes em áreas degradadas, incluindo a estimativa de parâmetros populacionais e outros aspectos ecológicos, é um passo importante para a obtenção do conhecimento do comportamento das diferentes espécies que possam compor determinada vegetação (CALEGARIO et al., 1993).

O uso da regeneração natural como método de recuperação da vegetação ao exigir menos mão-deobra e insumos se comparado à operação de plantio, pode reduzir significativamente o custo de estabelecimento da vegetação arbórea em áreas antropizadas. Porém, deve-se ressaltar que tal processo transcorrerá mais lentamente quando comparado ao método de regeneração artificial (BOTELHO e DAVIDE, 2002).

Segundo Costa (2004), o conhecimento do processo de regeneração natural em fragmentos perturbados e em áreas degradadas, em diferentes situações, permitirá a definição das condições necessárias para o uso da regeneração natural como método silvicultural para recuperação de ecossistemas florestais.

Com isso, o presente trabalho tem como objetivo avaliar a dinâmica da regeneração natural em duas nascentes em processo de recuperação no município de Lavras, MG.

\section{MATERIAL E MÉTODO}

\section{Localização e caracterização das áreas de estudo}

O estudo foi realizado em nascentes localizadas no município de Lavras na região sul do estado de Minas Gerais, estando assim caracterizadas: Nascente 1: Engloba uma área formada por três nascentes difusas, totalizando 4,7 ha, situada no Campus da Universidade Federal de Lavras - UFLA (21 ${ }^{\circ} 14^{\prime} 21,1^{\prime \prime} \mathrm{S}$ e $\left.44^{\circ} 58^{\prime} 02,4^{\prime \prime} \mathrm{W}\right)$, e Nascente 2: Nascente difusa com vários pontos de escoamento formando um brejo, localizada em propriedade particular vizinha à UFLA $\left(21^{\circ} 14^{\prime} 21,1^{\prime \prime} \mathrm{S}\right.$ e $\left.44^{\circ} 58^{\prime} 02,4^{\prime \prime} \mathrm{W}\right)$, totalizando uma área de 3,6 ha. Ambas as nascentes podem ser classificadas quanto ao estado de conservação como perturbadas.

As áreas estavam ocupadas com pastagem (capim Brachiaria sp.) em diferentes estágios de perturbação, com presença constante de gado. As áreas foram cercadas em dezembro de 2003. Nas áreas próximas à nascente 1 , existem alguns povoamentos antigos de eucaliptos e pinus. Já próximo à nascente 2 há um pequeno fragmento remanescente de floresta. As nascentes em estudo pertencem a sub-bacia do Ribeirão Vermelho afluente do Rio Grande. Os solos predominantes no entorno das nascentes são os Latossolos Amarelos.

De acordo com a classificação climática de Koppen o clima do município de Lavras é do tipo Cwa. A temperatura média anual é de $19,3^{\circ} \mathrm{C}$. A precipitação média anual é de $1.530 \mathrm{~mm}$, a evaporação total anual é de $1.343 \mathrm{~mm}$ e a umidade relativa média anual de 76\% (BRASIL, 1992).

A formação florestal primitiva das áreas em estudo pode ser classificada como Floresta Estacional Semidecidual Montana (IBGE, 1997).

\section{Caracterização do solo das nascentes}

Com o objetivo de caracterizar o solo das duas áreas foram analisados os parâmetros referentes às 
análises química e textural, compactação e umidade.

A análise química do solo, em que a nascente 1 foi dividida em duas áreas, pelo fato de o solo desta nascente, previamente à sua análise, apresentar visualmente glebas de diferentes colorações e texturas, foi realizada a partir de três amostras simples na profundidade de $0-20 \mathrm{~cm}$ para a formação de uma amostra composta (área 1), e a área 2 foi constituída por sete amostras simples. Na nascente 2 foram coletadas dez amostras simples na profundidade de $0-20 \mathrm{~cm}$ para a constituição de uma amostra composta. A análise foi efetuada de acordo com procedimentos recomendados pela EMBRAPA (1979) no Laboratório de Análise de Solos da UFLA.

A resistência mecânica do solo à penetração foi determinada em novembro/2006, utilizando-se o penetrômetro de impacto modelo IAA/PLANALSUCAR-STOLF, segundo metodologia preconizada por Stolf et al. (1983). Em cada local, foram amostrados vinte pontos na profundidade de $0-40 \mathrm{~cm}$. Os cálculos foram realizados com o apoio do programa PENETRON' (STOLF, 1991), tendo os valores, obtidos em $\mathrm{Kgf} / \mathrm{cm}^{2}$, sido transformados para MPa, multiplicando-se pela constante 0,098 .

A umidade do solo foi medida pelo período de um ano (Outubro/2005 a Novembro/2006), por meio do método gravimétrico (GARDNER, 1986), sendo coletadas amostras deformadas de solo em 47 pontos na nascente 1 e 49 na nascente 2, na profundidade de $0-20 \mathrm{~cm}$. A geoestatística foi utilizada como "ferramenta" para o estudo da variabilidade espacial da umidade do solo. As análises foram realizadas conforme sugerido por Mello (2004). O modelo exponencial ajustado pelo método da máxima verossimilhança (MV) foi utilizado a fim de descrever a variabilidade dos dados. De acordo com Souza et al. (2001); Souza et al. (2004a) e Souza et al. (2004b) o modelo exponencial é o modelo mais eficiente na descrição da variabilidade de atributos do solo. Todas as análises geoestatísticas foram realizadas no programa $\mathrm{R}$, por meio do pacote geoR, desenvolvido por Ribeiro Júnior e Diggle (2001).

\section{Levantamento florístico fitossociológico}

Para o levantamento florístico da regeneração natural, foram plotadas no total 122 parcelas de $5 \times 5$ $\mathrm{m}\left(25 \mathrm{~m}^{2}\right)$, sendo 76 parcelas na nascente 1 e 46 parcelas na nascente 2 . As parcelas foram distribuídas de forma sistemática e distanciadas a cada $10 \mathrm{~m}$ ao longo da transecção e a cada $20 \mathrm{~m}$ entre as transecções.

Considerou-se como regeneração natural todos os indivíduos arbustivo-arbóreos com DAP (Diâmetro Altura do Peito) inferior a $5 \mathrm{~cm}$ e altura superior a $0,10 \mathrm{~m}$. As coletas foram realizadas aos 18 e 24 meses após o cercamento das nascentes. Todos os indivíduos amostrados foram plaqueteados, identificados quanto à família, espécie e nome popular, e medidos a altura e DAS (Diâmetro Altura do Solo). O material botânico testemunho foi herborizado e depositado no herbário da Universidade Federal de Lavras (Herbário ESAL). As identificações foram feitas com base na literatura especializada e consulta a especialistas e coleções dos Herbários ESAL. As espécies foram classificadas nas famílias reconhecidas pelo sistema do Angiosperm Phylogeny Group II (APG, 2003).

Os indivíduos amostrados foram classificados em quatro classes de tamanho da regeneração natural, conforme adotado por Scolforo (2004) e adaptado para a definição de regeneração utilizada no presente trabalho. As classes de tamanho adotadas foram as seguintes: Classe I - plantas com altura $<0,3 \mathrm{~m}$; Classe II - plantas com altura entre 0,3 e 1,5 m; Classe III - plantas com altura $>1,5 \mathrm{~m}$ e $<$ 3,0 $\mathrm{m}$ e Classe IV plantas com altura $\geq 3,0 \mathrm{~m}$ e DAP $<5 \mathrm{~cm}$.

Os parâmetros estimados para a regeneração natural foram: frequência, densidade e dominância, em seus valores relativos, Valor de Importância (VI), Valor de Cobertura (VC), Índice de Regeneração, Classes de Tamanho Relativa da Regeneração Natural, de acordo com Finol (1971). Também foram calculados os índices de Diversidade de Shannon (H'), Equabilidade de Pielou (J'), conforme Brower e Zar (1984), e Similaridade de Jaccard (SJ).

\section{Dinâmica da regeneração natural}

Com base em Sheil et al. (1995, 2000), foram assumidas mudanças em tamanho populacional por intervalo de tempo em proporção constante do tamanho inicial da população e foram, assim, calculadas as taxas anuais médias de mortalidade $(\mathrm{M})$ e recrutamento $(\mathrm{R})$ de árvores individuais e taxas anuais médias de perda $(\mathrm{P})$ e ganho $(\mathrm{G})$ de área basal das árvores por meio das expressões exponenciais: 


$$
\begin{aligned}
& M=\{1-[(N 0-N m) / N 0] 1 / t\} * 100 ; \text { e } R=[1-(1-N r / N t) 1 / t] * 100 \\
& P=\{1-[(A B 0-A B m-A B d) / A B 0] 1 / t\} * 100 ; \text { e } G=\{1-[1-(A B r+A B g) / A B t] 1 / t\} * 100
\end{aligned}
$$

Em que t é o tempo decorrido entre os inventários, N0 e Nt são, respectivamente, as contagens inicial e final de árvores individuais, $\mathrm{Nm}$ e $\mathrm{Nr}$ são, respectivamente, o número de árvores mortas e recrutadas, $\mathrm{AB} 0$ e $\mathrm{ABt}$ são, respectivamente, as áreas basais inicial e final das árvores, $\mathrm{ABm}$ é a área basal das árvores mortas, $\mathrm{ABr}$ é a área basal dos recrutas e $\mathrm{ABd}$ e $\mathrm{ABg}$ são, respectivamente, o decremento (por meio de quebra ou perda parcial do tronco) e o incremento em área basal das árvores sobreviventes. Para expressar a dinâmica global, foram obtidas as taxas de rotatividade (turnover) em número de árvores (TN) e área basal (TAB) a partir, respectivamente, das médias das taxas de mortalidade e recrutamento e de perda e ganho (OLIVEIRAFILHO et al., 1997; WERNECK e FRANCESCHINELLI, 2004):

$T N=(M+R) / 2 ;$ e $T A B=(P+G) / 2$

Conforme Korning e Balslev (1994), foram também obtidas as taxas de mudança líquida no período, tanto para número de árvores $(\mathrm{ChN})$ como área basal $(\mathrm{ChAB})$, sendo utilizadas as equações:

$$
C h N=[(N t / N 0) 1 / t-1] * 100 ; \text { e } C h A B=[(A B t / A B 0) 1 / t-1] * 100
$$

\section{RESULTADOS E DISCUSSÃO}

\section{Caracterização do solo das nascentes}

Na Tabela 1, são apresentados os resultados referentes às análises químicas e granulométricas do solo das nascentes estudadas. A nascente 1 foi dividida em duas áreas, pelo fato dessas áreas apresentarem notadamente solos com diferentes colorações e texturas. Pode-se confirmar por meio da Tabela 1, que há grandes diferenças entre as características destes solos quanto ao nível de ferro, ao teor de matéria orgânica e a textura.

Observa-se que o solo das nascentes apresenta bons níveis de fertilidade, sendo que a grande maioria dos elementos analisados se apresenta com teores bastante satisfatórios para o desenvolvimento das espécies. Em ambas as nascentes apenas os teores de fósforo são considerados muito baixos.

Com relação à textura, o solo da área 2 (nascente 1) e da nascente 2 apresentam textura argilosa, ao passo que o solo da área 1 (nascente 1) possui textura média.

A Figura 1 apresenta a relação entre a profundidade do solo e a resistência deste à penetração para as nascentes 1 e 2 . Pode-se verificar que para as duas nascentes houve uma tendência semelhante de aumento da resistência à penetração do solo no intervalo de profundidade entre $5-15 \mathrm{~cm}$, mantendo valores acima de 1,88 $\mathrm{MPa}$ até a profundidade de $40 \mathrm{~cm}$. Tal comportamento pode estar relacionado à compactação subsuperficial causada pelo pisoteio do gado, uma vez que, anteriormente ao cercamento, realizado em dezembro/2003, as áreas eram utilizadas como pastagem. Observa-se também que a nascente 2 apresentou maior resistência do solo à penetração até $15 \mathrm{~cm}$ de profundidade. Maior resistência à penetração é um indicativo de maior densidade do solo, que apresenta menor porosidade, pois as partículas sólidas estão mais próximas umas das outras diminuindo assim, a capacidade de infiltração de água no solo, o que poderá refletir em uma menor taxa de armazenamento de água no solo e maior susceptibilidade ao escoamento superficial.

Segundo Alvarenga (2004), os valores críticos encontrados na literatura como restritivos ao sistema radicular, são divergentes e variam com o tipo de solo, equipamento utilizado na avaliação e a espécie em estudo, sendo que estes valores podem variar de 1,5 até 3,0 MPa. Soil Survey Staff(1993), propõe a seguinte classificação para a resistência à penetração do solo em MPa: extremamente baixa $(<0,01)$; muito baixa $(0,01$ a 0,1$)$; baixa $(0,1$ a 1,0$)$; moderada $(1,0$ a 2,0$)$; alta $(2,0$ a 4,0$)$; muito alta $(4,0$ a 8,0$)$ e extremamente alta $(>8,0)$. Nesse caso, a compactação nas duas áreas estudadas apresenta-se de moderada a alta. De acordo com Arshad et al. (1996), o crescimento de raízes pode ser limitado em solos com resistência à penetração maior que 2,0 MPa, valor observado nas duas áreas estudadas partindo da profundidade de $5-10 \mathrm{~cm}$. 
TABELA 1: Características físicas e químicas do solo.

TABLE 1: Soil physical and chemical characteristics.

\begin{tabular}{|c|c|c|c|c|c|c|c|}
\hline \multirow{3}{*}{ Elementos } & \multirow{3}{*}{ Unidade } & \multicolumn{4}{|c|}{ Nascente 1} & \multirow{2}{*}{\multicolumn{2}{|c|}{ Nascente 2}} \\
\hline & & \multicolumn{2}{|c|}{ Área 1} & \multicolumn{2}{|c|}{ Área 2} & & \\
\hline & & $\mathrm{R}$ & I & $\mathrm{R}$ & I & $\mathrm{R}$ & I \\
\hline $\mathrm{pH}$ em água $(1: 2,5)$ & & 5,9 & AM & 5,8 & AM & 6,3 & $\mathrm{AF}$ \\
\hline P (Fósforo Mehlich 1) & $\mathrm{mg} / \mathrm{dm}^{3}$ & 2 & MBx & 1,2 & $\mathrm{MBx}$ & 2,5 & MBx \\
\hline K (Potássio Mehlich 1) & $\mathrm{mg} / \mathrm{dm}^{3}$ & 87 & B & 67 & M & 123 & MB \\
\hline Ca (Cálcio) & cmolc/dm ${ }^{3}$ & 2 & M & 2,1 & M & 4,8 & MB \\
\hline Mg (Magnésio) & cmolc/dm ${ }^{3}$ & 0,5 & M & 0,7 & M & 1,6 & MB \\
\hline Al (Alumímio) & $\mathrm{cmolc} / \mathrm{dm}^{3}$ & 0,2 & MBx & 0,3 & $\mathrm{Bx}$ & 0 & MBx \\
\hline $\mathrm{H}+\mathrm{Al}$ (Acidez potencial) & $\mathrm{cmolc} / \mathrm{dm}^{3}$ & 2,6 & M & 5 & M & 2,9 & M \\
\hline SB (Soma de bases) & cmolc/dm ${ }^{3}$ & 2,7 & M & 3 & M & 6,7 & MB \\
\hline $\mathrm{t}$ (CTC efetiva) & $\mathrm{cmolc} / \mathrm{dm}^{3}$ & 2,9 & M & 3,3 & M & 6,7 & $\mathrm{~B}$ \\
\hline $\mathrm{T}(\mathrm{CTC}$ a $\mathrm{pH} 7,0)$ & $\mathrm{cmolc} / \mathrm{dm}^{3}$ & 5,3 & M & 8 & M & 9,6 & B \\
\hline V (Saturação por bases) & $\%$ & 51,1 & $\mathrm{M}$ & 37,3 & $\mathrm{Bx}$ & 69,8 & B \\
\hline m (Saturação por alumínio) & $\%$ & 7 & MBx & 9 & $\mathrm{MBx}$ & 0 & MBx \\
\hline MO (Matéria Orgânica) & $\mathrm{dag} / \mathrm{Kg}$ & 1,8 & $\mathrm{Bx}$ & 3,3 & M & 3 & M \\
\hline P-rem (Fósforo remanescente) & $\mathrm{mg} / \mathrm{L}$ & 21,7 & & 9,1 & & 9,7 & \\
\hline Zn (Zinco) & $\mathrm{mg} / \mathrm{dm}^{3}$ & 0,7 & $\mathrm{Bx}$ & 0,3 & $\mathrm{MBx}$ & 2,8 & A \\
\hline Fe (Ferro) & $\mathrm{mg} / \mathrm{dm}^{3}$ & 125,7 & A & 29,8 & M & 27,1 & M \\
\hline Mn (Manganês) & $\mathrm{mg} / \mathrm{dm}^{3}$ & 24,5 & A & 29,1 & A & 28,3 & $\mathrm{~A}$ \\
\hline $\mathrm{Cu}$ (Cobre) & $\mathrm{mg} / \mathrm{dm}^{3}$ & 0,9 & M & 0,3 & $\mathrm{MBx}$ & 2,1 & $\mathrm{~A}$ \\
\hline B (Boro) & $\mathrm{mg} / \mathrm{dm}^{3}$ & 1,2 & A & 0,4 & M & 1,2 & A \\
\hline S (Enxofre) & $\mathrm{mg} / \mathrm{dm}^{3}$ & 11,8 & B & 9,8 & MB & 14,3 & MB \\
\hline Areia & $\mathrm{dag} / \mathrm{Kg}$ & 37 & & 26 & & 19 & \\
\hline Silte & $\mathrm{dag} / \mathrm{Kg}$ & 40 & & 29 & & 31 & \\
\hline Argila & dag $/ \mathrm{Kg}$ & 23 & & 45 & & 50 & \\
\hline Classe textural & & & TM & & $\mathrm{AR}$ & & AR \\
\hline
\end{tabular}

Em que: $\mathrm{R}=$ Resultados e I = Interpretação; AM = Acidez Média; AF = Acidez Fraca; A = Alto; B = Bom; Bx = Baixo; $\mathrm{M}=$ Médio; $\mathrm{MB}=$ Muito Bom; $\mathrm{MBx}=$ Muito Baixo; $\mathrm{TM}=$ Textura Média e $\mathrm{AR}=$ Argilosa .

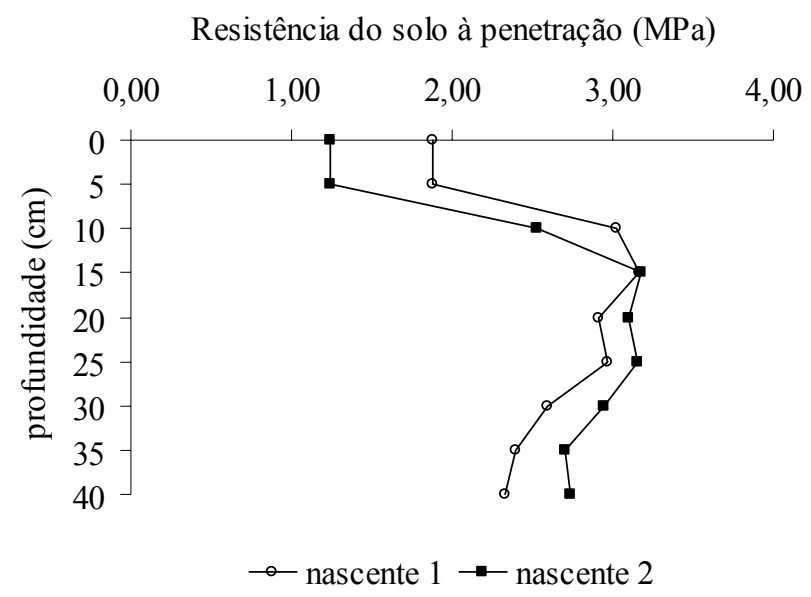

FIGURA 1: Valores médios de resistência do solo à penetração em função da profundidade do solo.

FIGURE 1: Average values of soil penetration resistance in function of the soil depth. 
Nota-se, na Figura 2, que, apesar da nascente 2 apresentar maiores valores de resistência à penetração do solo nas camadas superficiais $(0-15 \mathrm{~cm})$, esta apresentou maiores valores médios de umidade que a nascente 1, provavelmente pelo fato da nascente 1 apresentar um relevo mais acentuado.



FIGURA 2: Umidade do solo nas nascentes 1 e 2.

FIGURE 2: Soil moisture in springs 1 and 2.

Na Figura 3, (A-H) são apresentados os mapas de superfície da variabilidade espacial da umidade do solo durante o período avaliado (outubro/2005 a novembro/2006) para a nascente 1 . Percebe-se que, no mês de dezembro/2005, em relação a outubro/2005, houve um aumento da área com maior umidade, bem como nos valores das classes de umidade, atingindo $36 \%$ nas áreas mais úmidas, variando de 28 a $36 \%$.

Com relação aos meses de fevereiro e março/2006, observam-se a formação de duas áreas de maior umidade localizadas em locais distintos na área, próximos à região de formação dos pontos de vazão.

No período compreendido entre o mês de março a julho/2006, verifica-se uma redução nas áreas de maior umidade e consequente aumento das áreas de menor umidade. A umidade do solo atingiu seus menores valores, de 15 a $30 \%$, no mês de julho/2006.

Já a partir do mês de setembro/2006, verifica-se novamente o aumento das faixas de maior umidade, em consequência do início do período chuvoso. As regiões que apresentam uma menor umidade (áreas mais escuras no mapa) são caracterizadas por apresentar um terreno mais inclinado, favorecendo o escoamento superficial, enquanto que as áreas mais úmidas tratam-se das áreas mais próximas ao ponto de vazão das nascentes, portanto mais próximas do nível de saturamento de umidade do solo. Nas regiões de menor umidade, observa-se também que há uma menor cobertura do capim Brachiaria sp., ao passo que nas áreas mais úmidas (coloração mais clara) o capim se apresenta como uma "manta" sobre o solo, resultando na formação de grande quantidade de cobertura morta, a qual favorece uma maior absorção de água pelo solo.

O parâmetro umidade do solo apresentou, durante o período avaliado, gradiente crescente de umidade com o aumento da distância do ponto de vazão da nascente (Figura 4). Observa-se que assim como para a nascente 1, naqueles meses em que foram registradas as maiores precipitações, se constatou a formação de áreas com maiores valores de umidade do solo. Tais áreas se situam próximas ao local de surgimento da nascente. 


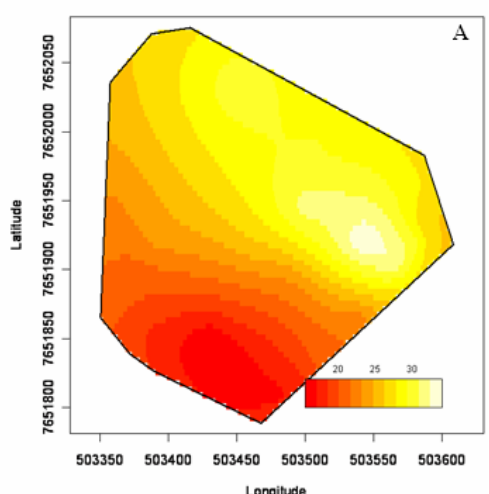

Longitude

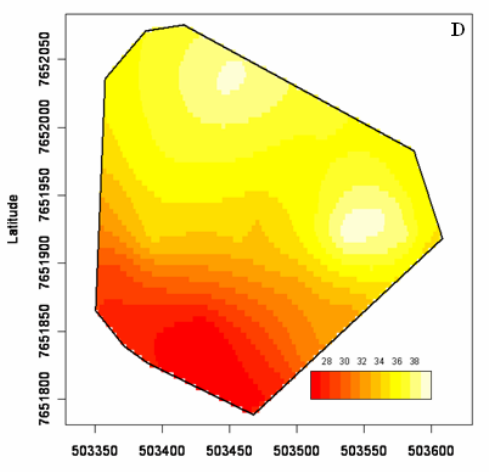

Longitude

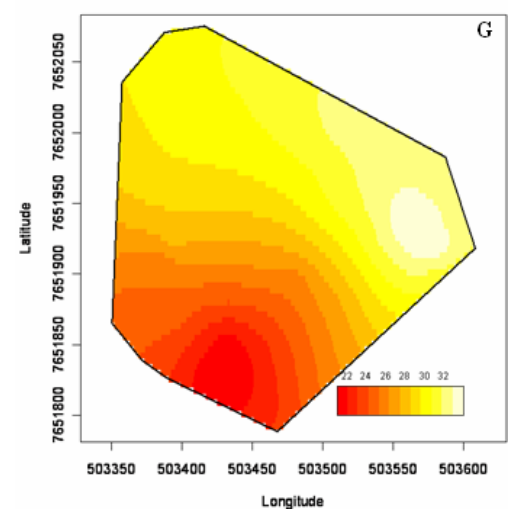

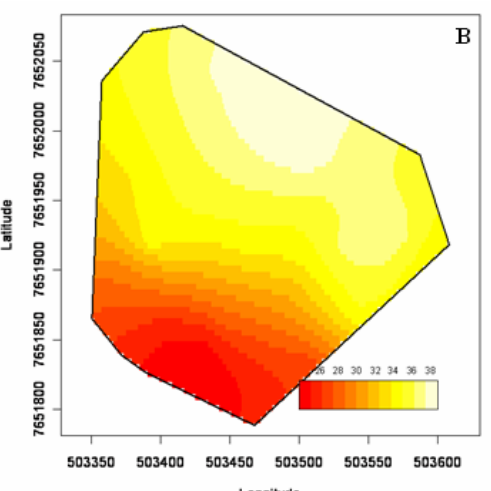

Longitude
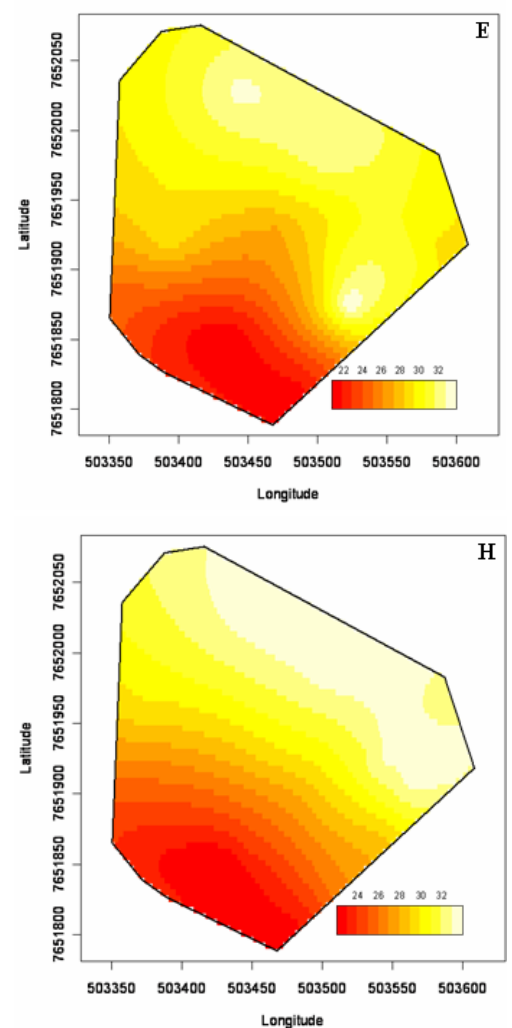

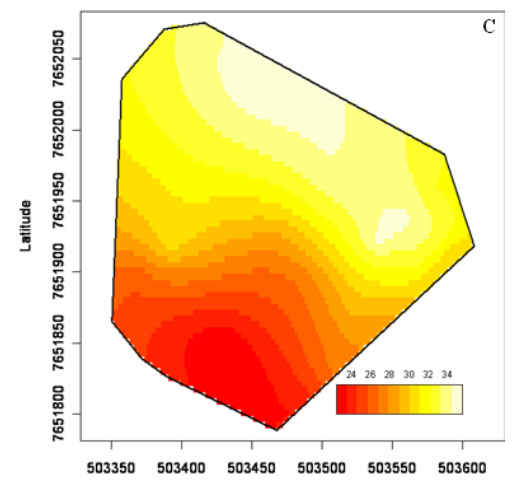

Longitude

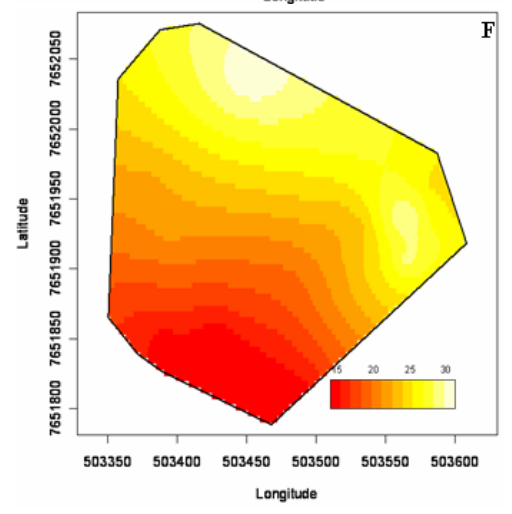

FIGURA 3: Distribuição espacial da umidade do solo (\%) no período de outubro de 2005 a julho de 2006 na nascente 1. Em que: A (outubro 2005), B (dezembro de 2005), C (fevereiro de 2006), D (março de 2006), E (maio de 2006), F (junho de 2006), G (setembro de 2006) e H (novembro de 2006).

FIGURE 3: Soil moisture spatial distribution (\%) in the period of October/2005 to July/2006 in spring 1. In which: A (October/2005), B (December/2005), C (February/2006), D (March/2006), E (May/2006), F (June/2006), G (September/2006) and H (November/2006).

Ao contrário da nascente 1 , na nascente 2 , os maiores valores de umidade do solo foram registrados para o mês de março/2006, provavelmente em razão da elevada precipitação e pela influência de uma lagoa localizada a jusante do ponto de vazão da nascente. Naquelas áreas onde se observam os menores valores de umidade do solo (sentido dos menores valores de latitude e longitude), verifica-se uma maior resistência do solo à penetração, sendo um solo altamente compactado, o qual já foi utilizado anteriormente como área de empréstimo. 

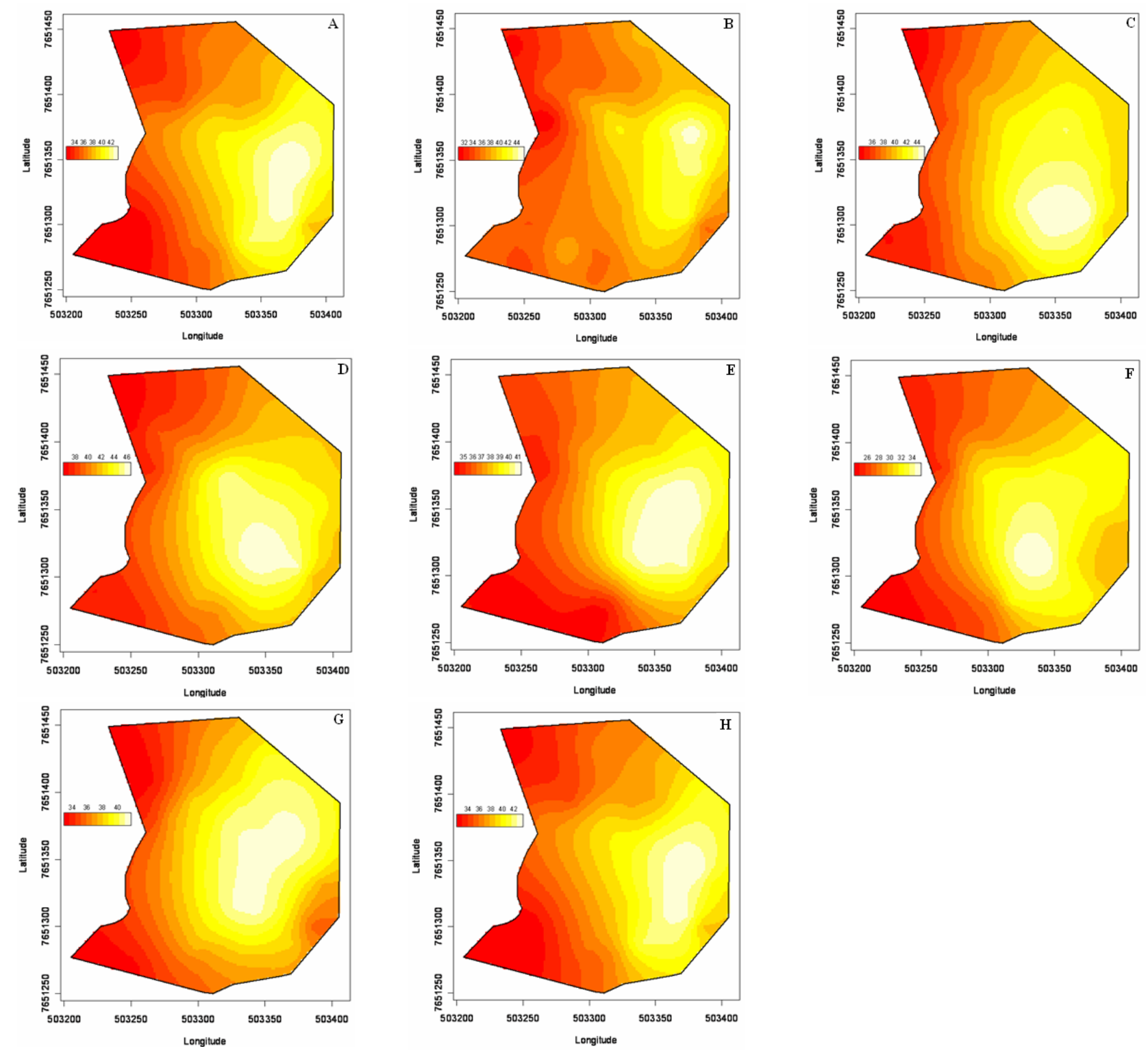

FIGURA 4: Distribuição espacial da umidade do solo (\%) no período de outubro/2005 a julho/2006 na nascente 2. Em que: A (outubro/2005), B (dezembro/2005), C (fevereiro/2006), D (março/2006), E (maio/2006), F (junho/2006), G (setembro/2006) e H (novembro/2006).

FIGURE 4: Soil moisture spatial distribution (\%) in the period of October/2005 to July/2006 in spring 2. In which: A (October/2005), B (December/2005), C (February/2006), D (March/2006), E (May/2006), F (June/2006), G (September/2006) and H (November/2006).

\section{Composição florística e estrutura da comunidade}

No levantamento florístico da regeneração natural, para as duas nascentes estudadas, foram amostrados nos dois inventários um total de 524 indivíduos pertencentes a 24 famílias e 55 espécies. Na Tabela 2, são apresentadas as famílias e espécies registradas e os seus respectivos números de indivíduos.

$\mathrm{Na}$ nascente 1, foram registrados, na primeira e segunda avaliação, respectivamente, 162 e 216 indivíduos, pertencentes a oito famílias e 13 espécies. As famílias que se destacaram em relação ao número de espécies foram: Asteraceae (4), Fabaceae Faboideae (2) e Solanaceae (2), contribuindo juntas com $61,54 \%$ das espécies amostradas, tanto na primeira como na segunda avaliação.

$\mathrm{Na}$ nascente 2, foram amostrados 266 e 308 indivíduos, 22 e 23 famílias, 47 e 51 espécies, na primeira e segunda avaliação respectivamente. As famílias Fabaceae Faboideae (5), Myrtaceae (5), Solanaceae (5), Asteraceae (4), Lauraceae (4), Anacardiaceae (3), Annonaceae (3), Fabaceae 
Caesalpinoideae (2), Salicaceae (2) e Melastomataceae (2) apresentaram os maiores números de espécies na primeira avaliação, contribuindo com $74,47 \%$ do total de espécies. Já na segunda avaliação as famílias Myrtaceae (6), Fabaceae Faboideae (5), Anacardiaceae (4), Asteraceae (4), Lauraceae (4), Solanaceae (4), Annonaceae (3), Salicaceae (3), Fabaceae Caesalpinoideae (2), Melastomataceae (2) e Rubiaceae (2) apresentaram os maiores números de espécies, contribuindo com $76,47 \%$ das espécies registradas. Todas essas famílias também se destacaram, em relação ao número de espécies registradas, nos trabalhos desenvolvidos por Pinto (2003) e Alvarenga (2004), avaliando nascentes da mesma região deste presente estudo.

A nascente 1 apresentou, na primeira e segunda avaliação, quatro espécies com um único indivíduo amostrado. Já a nascente 2 apresentou, 14 e 13 espécies com um único indivíduo amostrado, na primeira e segunda avaliação respectivamente.

Observa-se diferença significativa no número de espécies e no número de indivíduos entre as duas áreas, o que reflete a diferença na qualidade do sítio e na distância das fontes de sementes.

Observa-se que, ao final do período de monitoramento, o número de indivíduos aumentou de 428 para 524 indivíduos num período de seis meses (18 e 24 meses após o isolamento das áreas). A nascente 1 apresentou 54 novos indivíduos na segunda avaliação, e a nascente 242 novos indivíduos, representando um aumento de $33,33 \%$ e $15,8 \%$ respectivamente.

Esses valores podem ser considerados significativos, pois é grande a ocorrência de capim Brachiaria sp. nas áreas estudadas, dificultando o estabelecimento das espécies por meio da regeneração natural. Botelho e Davide (2002) afirmam que, na fase de estabelecimento e crescimento inicial da regeneração, a existência de plantas invasoras pode comprometer totalmente esse estabelecimento, impedindo a germinação e emergência das plântulas e causando alta mortalidade.

Na nascente 1, não houve aumento do número de espécies entre a primeira e segunda avaliação. Já a nascente 2 apresentou incremento de quatro novas espécies ao final do período de monitoramento.

TABELA 2: Relação das espécies registradas na regeneração natural, na nascente 1 (N1) e na nascente 2 (N2), na primeira e segunda avaliação, em ordem alfabética de famílias e espécies, seguidas dos seus respectivos números de indivíduos. Em que: $\mathrm{GE}=$ grupo ecológico $(\mathrm{P}=$ pioneira; $\mathrm{CL}=$ clímax exigente de luz e $\mathrm{CS}=$ clímax tolerante à sombra).

TABLE 2: Species registered in natural regeneration, in spring 1(N1) and spring 2 (N2), in first and second evaluation, in alphabetical order of families and species, following their respective individuals numbers. In which: $\mathrm{GE}=$ ecological group $(\mathrm{P}=$ pioneer; $\mathrm{CL}=$ demanding climax of light and $\mathrm{CS}=$ tolerant climax to the shade).

\begin{tabular}{|c|c|c|c|c|c|c|c|c|}
\hline \multirow{2}{*}{ Família } & \multirow{2}{*}{ Espécie } & \multirow{2}{*}{ GE } & \multicolumn{3}{|c|}{ Avaliação 1} & \multicolumn{3}{|c|}{ Avaliação 2} \\
\hline & & & N1 & N2 & Total & N1 & $\mathrm{N} 2$ & Total \\
\hline Anacardiaceae & Lithraea molleoides (Vell.) Engl. & $\mathrm{P}$ & 8 & 6 & 14 & 13 & 7 & 20 \\
\hline Anacardiaceae & Mangifera indica $\mathrm{L}$. & $\mathrm{CL}$ & - & 1 & 1 & - & 1 & 1 \\
\hline Anacardiaceae & Tapirira guianensis Aubl. & $\mathrm{CL}$ & - & - & - & - & 1 & 1 \\
\hline Anacardiaceae & Tapirira obtusa (Benth.) B.D.Mitch. & $\mathrm{CL}$ & - & 1 & 1 & - & 1 & 1 \\
\hline Annonaceae & Rollinia laurifolia Schltdl. & $\mathrm{CL}$ & - & 5 & 5 & - & 4 & 4 \\
\hline Anno & Rollinia sericea (R.E.Fr.) R.E.Fr. & $\mathrm{CL}$ & - & 1 & 1 & - & 1 & 1 \\
\hline Annonaceae & Xylopia brasiliensis Spreng. & $\mathrm{CS}$ & - & 1 & 1 & - & 1 & 1 \\
\hline$A$ & $\begin{array}{l}\text { Acrocomia aculeata (Jacq.) Lodd. ex } \\
\text { Mart. }\end{array}$ & $\mathrm{CL}$ & - & 12 & 12 & - & 10 & 10 \\
\hline Aste & Baccharis dracunculifolia DC. & $\mathrm{P}$ & 85 & 9 & 94 & 112 & 7 & 119 \\
\hline Aster & Gochnatia polymorpha (Less.) Cabrera & $\mathrm{P}$ & 1 & 1 & 2 & 2 & 2 & 4 \\
\hline Asteraceae & Vernonia ferruginea Less. & $\mathrm{P}$ & 31 & 8 & 39 & 45 & 11 & 56 \\
\hline Asteraceae & Vernonia polyanthes Less. & $\mathrm{P}$ & 8 & 31 & 39 & 9 & 27 & 36 \\
\hline Cannabaceae & Celtis iguanaea (Jacq.) Sarg. & $\mathrm{P}$ & 2 & 19 & 21 & 2 & 18 & 20 \\
\hline
\end{tabular}


TABELA 2: Continuação...

TABLE 2: Continuation...

\begin{tabular}{|c|c|c|c|c|c|c|c|c|}
\hline \multirow{2}{*}{ Família } & \multirow{2}{*}{ Espécie } & \multirow{2}{*}{ GE } & \multicolumn{3}{|c|}{ Avaliação 1} & \multicolumn{3}{|c|}{ Avaliação 2} \\
\hline & & & N1 & N2 & Total & N1 & N2 & Total \\
\hline $\begin{array}{l}\text { Fabaceae } \\
\text { Caesalpinoideae }\end{array}$ & Copaifera langsdorffii Desf. & $\mathrm{CS}$ & - & 14 & 14 & - & 16 & 16 \\
\hline $\begin{array}{l}\text { Fabaceae } \\
\text { Caesalpinoideae }\end{array}$ & $\begin{array}{l}\text { Senna macranthera (DC. et Callad.) } \\
\text { H.S. }\end{array}$ & $\mathrm{P}$ & - & 2 & 2 & - & 2 & 2 \\
\hline $\begin{array}{l}\text { Fabaceae } \\
\text { Faboideae }\end{array}$ & $\begin{array}{l}\text { Lonchocarpus guillemineanus (Tul.) } \\
\text { Malme }\end{array}$ & CL & - & 1 & 1 & - & 1 & 1 \\
\hline $\begin{array}{l}\text { Fabaceae } \\
\text { Faboideae }\end{array}$ & Machaerium hirtum (Vell.) Stellfeld & $\mathrm{CL}$ & - & 5 & 5 & - & 5 & 5 \\
\hline $\begin{array}{l}\text { Fabaceae } \\
\text { Faboideae }\end{array}$ & Machaerium nictitans (Vell.) Benth & $\mathrm{CL}$ & 1 & 5 & 6 & 1 & 10 & 11 \\
\hline $\begin{array}{l}\text { Fabaceae } \\
\text { Faboideae }\end{array}$ & Machaerium stipitatum (DC.) Vogel & $\mathrm{CL}$ & - & 1 & 1 & - & 3 & 3 \\
\hline $\begin{array}{l}\text { Fabaceae } \\
\text { Faboideae }\end{array}$ & Platipodium elegans Vogel & $\mathrm{CL}$ & 1 & - & 1 & 1 & - & 1 \\
\hline $\begin{array}{l}\text { Fabaceae } \\
\text { Faboideae }\end{array}$ & Sesbania sesban (L.) Merr. & $\mathrm{CL}$ & - & 3 & 3 & - & 2 & 2 \\
\hline $\begin{array}{l}\text { Fabaceae } \\
\text { Mimosoideae }\end{array}$ & Acacia polyphylla DC. & P & - & 3 & 3 & - & 6 & 6 \\
\hline Lamiaceae & Aegiphila sellowiana Cham. & $\mathrm{P}$ & 2 & - & 2 & 4 & - & 4 \\
\hline Lauraceae & Nectandra lanceolata Nees & $\mathrm{CS}$ & - & 2 & 2 & - & 3 & 3 \\
\hline Lauraceae & Nectandra nitidula Nees \& Mart. & $\mathrm{CL}$ & - & 34 & 34 & - & 47 & 47 \\
\hline Lauraceae & Ocotea pulchella (Nees) Mez & $\mathrm{CL}$ & - & 10 & 10 & - & 9 & 9 \\
\hline Lauraceae & Persea pyrifolia (D. Don) Spreng. & $\mathrm{CL}$ & - & 5 & 5 & - & 4 & 4 \\
\hline Melastomataceae & Miconia albicans (Sw.) Triana & $\mathrm{P}$ & - & 1 & 1 & - & 1 & 1 \\
\hline Melastomataceae & Miconia sp. & $\mathrm{nc}$ & - & 1 & 1 & - & 1 & 1 \\
\hline Meliaceae & Cedrela fissilis Vell. & $\mathrm{CL}$ & - & 6 & 6 & - & 14 & 14 \\
\hline Moraceae & Maclura tinctoria (L.) D.Don. ex Steud. & $\mathrm{P}$ & - & - & - & - & 1 & 1 \\
\hline Myrsinaceae & Myrsine umbellata Mart. & $\mathrm{CL}$ & - & 2 & 2 & - & 2 & 2 \\
\hline Myrtaceae & Campomanesia pubescens (DC.) O.Berg & $\mathrm{CL}$ & 1 & - & 1 & 1 & - & 1 \\
\hline Myrtaceae & Eugenia florida DC. & $\mathrm{CS}$ & - & 6 & 6 & - & 8 & 8 \\
\hline Myrtaceae & Myrcia fallax (Rich.) DC. & $\mathrm{CL}$ & - & - & - & - & 1 & 1 \\
\hline Myrtaceae & Myrcia tomentosa (Aubl.) DC. & $\mathrm{CL}$ & - & 2 & 2 & - & 2 & 2 \\
\hline Myrtaceae & Myrcia velutina O.Berg & $\mathrm{CS}$ & - & 11 & 11 & - & 8 & 8 \\
\hline Myrtaceae & Myrciaria cauliflora (Mart.) O. Berg & $\mathrm{CS}$ & - & 1 & 1 & - & 3 & 3 \\
\hline Myrtaceae & Psidium guajava $\mathrm{L}$. & $\mathrm{CL}$ & - & 3 & 3 & - & 8 & 8 \\
\hline Piperaceae & Piper aduncum L. & $\mathrm{P}$ & 8 & 11 & 19 & 10 & 15 & 25 \\
\hline Rhamnaceae & Colubrina cf glandulosa Perkins & CL & - & 3 & 3 & - & 2 & 2 \\
\hline Rosaceae & Eriobotrya japonica (Thunb.) Lindl. & $\mathrm{Nc}$ & - & 1 & 1 & - & 1 & 1 \\
\hline Rubiaceae & Psychotria sessilis Vell. & $P$ & - & - & - & - & 2 & 2 \\
\hline Rubiaceae & Randia nitida (Kunth) DC. & $\mathrm{CS}$ & - & 2 & 2 & - & 2 & 2 \\
\hline Rutaceae & Zanthoxylum rhoifolium Lam. & $\mathrm{CL}$ & - & 2 & 2 & - & 2 & 2 \\
\hline Salicaceae & Casearia decandra Jacq. & $\mathrm{CS}$ & - & 4 & 4 & - & 6 & 6 \\
\hline Salicaceae & Casearia lasiophylla Eichler & $\mathrm{CL}$ & - & 1 & 1 & - & 1 & 1 \\
\hline Salicaceae & Casearia sylvestris $\mathrm{Sw}$. & $\mathrm{P}$ & - & - & - & - & 2 & 2 \\
\hline
\end{tabular}


TABELA 2: Continuação...

TABLE 2: Continuation...

\begin{tabular}{|c|c|c|c|c|c|c|c|c|}
\hline \multirow{2}{*}{ Família } & \multirow{2}{*}{ Espécie } & \multirow{2}{*}{ GE } & \multicolumn{3}{|c|}{ Avaliação 1} & \multicolumn{3}{|c|}{ Avaliação 2} \\
\hline & & & N1 & $\mathrm{N} 2$ & Total & N1 & $\mathrm{N} 2$ & Total \\
\hline Sapotaceae & $\begin{array}{l}\text { Chrysophyllum marginatum (Hook. \& } \\
\text { Arn.) Radlk. }\end{array}$ & $\mathrm{CL}$ & - & 7 & 7 & - & 8 & 8 \\
\hline Solanaceae & Solanum cernuum Vell. & $\mathrm{CS}$ & - & 1 & 1 & - & - & - \\
\hline Solanaceae & Solanum granuloso-leprosum Dunal & $\mathrm{P}$ & - & 5 & 5 & - & 3 & 3 \\
\hline Solanaceae & Solanum lycocarpum A.St.-Hil. & $\mathrm{P}$ & 12 & 9 & 21 & 15 & 7 & 22 \\
\hline Solanaceae & Solanum paniculatum L. & $\mathrm{P}$ & - & 2 & 2 & - & 3 & 3 \\
\hline Solanaceae & Solanum pseudoquina A.St.-Hil. & $\mathrm{CL}$ & 2 & 4 & 6 & 1 & 5 & 6 \\
\hline Urticaceae & Cecropia pachystachya Trécul & $\mathrm{P}$ & - & 1 & 1 & - & 1 & 1 \\
\hline Total & & & 162 & 266 & 428 & 216 & 308 & 524 \\
\hline
\end{tabular}

Os parâmetros fitossociológicos foram calculados para a primeira e segunda avaliação nas nascentes 1 e 2, estando apresentados nas Tabelas 3 e 4 e Figuras 5 e 6.

Para a nascente 1 , com relação a distribuição das espécies na área, constatou-se que as espécies Baccharis dracunculifolia, Vernonia ferruginea, Solanum lycocarpum, Lithraea molleoides e Vernonia polyanthes se destacaram das demais em ambas as avaliações.

Observa-se, na Tabela 3, que essas mesmas espécies, além da espécie Piper aduncum, também se destacaram em relação ao parâmetro densidade relativa, apresentando 93,84 e 94,44\% da densidade relativa total na primeira e segunda avaliação respectivamente. Já ao analisar o parâmetro dominância relativa, podese observar que as espécies Vernonia ferruginea e Solanum lycocarpum apresentaram maiores valores que a espécie Baccharis dracunculifolia que havia se destacado das demais em relação aos parâmetros anteriores. Isto pode ser explicado pelo fato de os indivíduos amostrados da espécie Baccharis dracunculifolia possuírem menores valores de área basal, quando comparados às duas espécies anteriores, em função de porte característico da espécie.

Outro fato importante a ser considerado se refere à diferença na classificação das espécies em relação aos parâmetros Valor de Importância (VI) e Índice de Regeneração Natural (RN), os quais expressam a importância de cada espécie na regeneração natural. Quando as espécies são analisadas em relação ao VI, nota-se que a espécie Vernonia ferruginea se destaca em relação a todas as demais. Já em relação ao parâmetro regeneração natural, a espécie Baccharis dracunculifolia possui maior importância. Essa diferença pode ser explicada devido ao fato de que tais índices são compostos por parâmetros diferentes, sendo que o VI inclui o valor de dominância calculado com base na área basal. Vale ressaltar que as seis espécies com maior VI e RN pertencem ao grupo ecológico das pioneiras, o que evidência a importância dessas espécies na colonização e estabelecimento nas áreas degradadas e ou, perturbadas. Tais espécies são de extrema importância para o inicio do processo de recuperação, pois tem a função de proteger o solo e proporcionar condições ideais para que outras espécies de estágios de vida mais avançado possam surgir. Espécies como Baccharis dracunculifolia, Solanum lycocarpum, Lithraea molleoides e Vernonia polyanthes também foram as de maior importância na regeneração natural em outros estudos realizados em áreas de nascentes na mesma região (VILELA, 2006).

Essas espécies, com exceção de Lithraea molleoides, são espécies de portes arbustivos típicas de ambientes que sofrem distúrbios freqüentes, colonizando áreas abertas em processo de recuperação. Já a espécie Lithraea molleoides, de porte arbóreo, apresenta-se bem distribuída na região, estando presente em diversos levantamentos florísticos já realizados (PINTO, 2003; RODRIGUES et al., 2003; ALVARENGA, 2004), sendo frequentemente constatadas em áreas perturbadas, especialmente nas bordas de fragmentos de matas nativas. 
TABELA 3: Resumo da análise fitossociológica para a nascente 1, avaliação 1 e 2 , apresentando a frequência relativa $(\mathrm{FR} \%)$, a densidade relativa $(\mathrm{DR} \%)$, a dominância relativa $(\mathrm{DoR} \%)$, o valor de importância (VI\%), o valor de cobertura (VC\%), a classe de tamanho relativa da regeneração natural (CTRRN\%) e o índice de regeneração natural (RN\%).

TABLE 3: Summary of fitossociologic analysis to spring 1, first and second evaluation, presenting the relative frequency $(\mathrm{FR} \%)$, relative density $(\mathrm{DR} \%)$, relative dominance (DoR\%), importance value (VI\%), cover value ( $\mathrm{VC} \%)$, relative class of size of the natural regeneration (CTRRN\%) and natural regeneration index (RN\%).

\begin{tabular}{|c|c|c|c|c|c|c|c|}
\hline \multicolumn{8}{|c|}{$1^{\mathrm{a}}$ avaliação } \\
\hline Espécie & FR & DR & DoR & VI & $\mathrm{VC}$ & CTRRN & $\mathrm{RN}$ \\
\hline Baccharis dracunculifolia & 28,57 & 52,47 & 9,37 & 90,41 & 61,84 & 57,10 & 46,05 \\
\hline Vernonia ferruginea & 25,71 & 19,14 & 56,18 & 101,03 & 75,31 & 14,68 & 19,84 \\
\hline Solanum lycocarpum & 10,00 & 7,41 & 16,43 & 33,84 & 23,84 & 5,98 & 7,79 \\
\hline Lithraea molleoides & 10,00 & 4,94 & 4,92 & 19,86 & 9,86 & 5,34 & 6,76 \\
\hline Vernonia polyanthes & 8,57 & 4,94 & 8,13 & 21,64 & 13,07 & 4,76 & 6,09 \\
\hline Piper aduncum & 4,29 & 4,94 & 0,82 & 10,04 & 5,76 & 5,91 & 5,05 \\
\hline Aegiphila sellowiana & 2,86 & 1,23 & 0,29 & 4,38 & 1,53 & 1,48 & 1,86 \\
\hline Solanum pseudoquina & 2,86 & 1,23 & 0,28 & 4,37 & 1,51 & 1,48 & 1,86 \\
\hline Celtis iguanaea & 1,43 & 1,23 & 2,18 & 4,84 & 3,41 & 0,32 & 0,99 \\
\hline Campomanesia pubescens & 1,43 & 0,62 & 0,05 & 2,09 & 0,66 & 0,74 & 0,93 \\
\hline Gochnatia polymorpha & 1,43 & 0,62 & 0,08 & 2,13 & 0,70 & 0,74 & 0,93 \\
\hline Machaerium nictitans & 1,43 & 0,62 & 1,11 & 3,16 & 1,73 & 0,74 & 0,93 \\
\hline Platipodium elegans & 1,43 & 0,62 & 0,16 & 2,21 & 0,78 & 0,74 & 0,93 \\
\hline Total & 100,00 & 100,00 & 100,00 & 300,00 & 200,00 & 100,00 & 100,00 \\
\hline \multicolumn{8}{|c|}{$2^{\mathrm{a}}$ avaliação } \\
\hline Espécie & FR & $\overline{D R}$ & DoR & VI & $\mathrm{VC}$ & CTRRN & $\mathrm{RN}$ \\
\hline Baccharis dracunculifolia & 29,76 & 51,85 & 11,75 & 93,36 & 63,60 & 54,30 & 45,31 \\
\hline Vernonia ferruginea & 21,43 & 20,83 & 58,07 & 100,33 & 78,90 & 19,20 & 20,49 \\
\hline Lithraea molleoides & 11,90 & 6,02 & 6,98 & 24,91 & 13,00 & 5,60 & 7,84 \\
\hline Solanum lycocarpum & 10,71 & 6,94 & 13,75 & 31,41 & 20,70 & 5,69 & 7,78 \\
\hline Vernonia polyanthes & 8,33 & 4,17 & 4,00 & 16,50 & 8,17 & 3,95 & 5,48 \\
\hline Piper aduncum & 5,95 & 4,63 & 0,90 & 11,48 & 5,53 & 5,87 & 5,48 \\
\hline Aegiphila sellowiana & 4,76 & 1,85 & 0,74 & 7,36 & 2,59 & 2,02 & 2,88 \\
\hline Gochnatia polymorpha & 1,19 & 0,93 & 0,65 & 2,76 & 1,57 & 0,84 & 0,99 \\
\hline Celtis iguanaea & 1,19 & 0,93 & 2,30 & 4,41 & 3,22 & 0,51 & 0,88 \\
\hline Campomanesia pubescens & 1,19 & 0,46 & 0,05 & 1,71 & 0,52 & 0,59 & 0,75 \\
\hline Platipodium elegans & 1,19 & 0,46 & 0,10 & 1,76 & 0,57 & 0,59 & 0,75 \\
\hline Solanum pseudoquina & 1,19 & 0,46 & 0,06 & 1,72 & 0,53 & 0,59 & 0,75 \\
\hline Machaerium nictitans & 1,19 & 0,46 & 0,64 & 2,29 & 1,10 & 0,25 & 0,64 \\
\hline Total & 100,00 & 100,00 & 100,00 & 300,00 & 200,00 & 100,00 & 100,00 \\
\hline
\end{tabular}

$\mathrm{Na}$ Figura 5 (a e b), são apresentadas as densidades absolutas por classe de tamanho das seis espécies com maior índice de regeneração natural, para a nascente 1 na primeira e segunda avaliação, respectivamente. Observa-se que apenas a espécie Lithraea molleoides, na segunda avaliação, apresentou indivíduos em todas as classes de tamanho. Higuchi (2003) e Pereira et al. (2001), ressaltam que espécies que apresentam seus indivíduos distribuídos em todas as classes de tamanho têm maior potencial de desenvolvimento e estabelecimento.

A espécie Piper aduncum posssui indivíduos apenas na classe de tamanho 2. Baccharis dracunculifolia apresentou seus indivíduos distribuídos nas classes de tamanho 1, 2 e 3. Os indivíduos da espécie Vernonia polyanthes estão inseridos nas classes de tamanho 2 e 3. A espécie Vernonia ferruginea, que possui o segundo maior valor do índice regeneração natural, apresentou seus indivíduos distribuídos nas 
classes de tamanho 1, 2 e 3 na primeira avaliação. Enquanto na segunda avaliação, para essa mesma espécie, os indivíduos são distribuídos nas classes de tamanho 2, 3 e 4. Já a espécie Solanum lycocarpum, na primeira avaliação, apresentava indivíduos apenas nas classes de tamanho 2 e 3 , ao passo que na segunda avaliação, essa mesma espécie era representada também por indivíduos na classe de tamanho 4.

Na primeira avaliação, verifica-se que a classe de tamanho 1 possui 3,09\% dos indivíduos, a classe de tamanho 2 apresenta 79,63\%, a classe de tamanho 3 tem 17,28\% do total de indivíduos, enquanto a classe de tamanho 4 não possui nenhum indivíduo. Já na segunda avaliação, observa-se que a classe de tamanho 1 é representada por $1,85 \%$ dos indivíduos, a classe de tamanho 2 possui $66,2 \%$, e as classes de tamanho 3 e 4 apresentam 28,7 e $3,24 \%$ do total de indivíduos registrados respectivamente.

Observa-se, portanto, no período de 6 meses, um incremento na altura das espécies aumentando o número de indivíduos nas maiores classes de tamanho, acima de 1,5 metros. A espécie arbustiva Baccharis dracunculifolia apresentou incremento significativo de plantas para a classe 3, entretanto não alcançando a classe 4 ( $\geq 3 \mathrm{~m}$ ), em função de seu pequeno porte.

$\mathrm{Na}$ Tabela 4, são apresentados os cálculos dos parâmetros fitossociológicos realizados para as espécies registradas na nascente 2 na primeira e segunda avaliação.


FIGURA 5: Distribuição da densidade por classe de tamanho da regeneração natural, para as seis espécies de maior RN, registradas na nascente 1, na primeira(a) e segunda (b) avaliação (C1: plantas com altura menor que $0,3 \mathrm{~m} ; \mathrm{C} 2$ : plantas com altura entre 0,3 e 1,5 m, C3: plantas com altura maior que $1,5 \mathrm{~m}$ e menor que $3,0 \mathrm{~m}$ e C4: plantas com altura maior ou igual a $3,0 \mathrm{~m}$ e com DAP menor que $5 \mathrm{~cm}$ ).

FIGURE 5: Distribution of density per class of size of natural regeneration, for the six species of larger RN, registered in spring 1, in first (a) and second (b) evaluation ( $\mathrm{Cl}$ : plants with height smaller than $0.3 \mathrm{~m}$; C2: plants with height between 0.3 and $1.5 \mathrm{~m}$; 3 : plants with height larger than $1.5 \mathrm{~m}$ and smaller than $3.0 \mathrm{~m}$ and $\mathrm{C} 4$ : plants with height larger or equal to $3.0 \mathrm{~m}$ and with DAP smaller than $5 \mathrm{~cm}$ ). 
Na primeira avaliação, as espécies que se destacaram quanto ao parâmetro densidade relativa foram: Nectandra nitidula (12,78\%), Vernonia polyanthes (11,65\%), Celtis iguanaea (7,14\%), Copaifera langsdorffii (5,26\%) e Acrocomia aculeata (4,51\%), contribuindo juntas com 41,34\% da densidade relativa total.

Com relação à segunda avaliação, as espécies Nectandra nitidula (15,26\%), Vernonia polyanthes (8,77\%), Celtis iguanaea (5,84\%), Copaifera langsdorffii (5,19\%), Piper aduncum (4,87\%) e Cedrella fissilis (4,55\%), apresentaram juntas $44,48 \%$ da densidade relativa total.

Observa-se que as seis espécies que apresentaram maior valor de frequência relativa para a avaliação 1 foram: Vernonia polyanthes, Celtis iguanaea, Acrocomia aculeata, Nectandra nitidula, Piper aduncum e Lithraea molleoides. Já na avaliação 2, além destas, as espécies Machaerium nictitans e Cedrela fissilis também se destacaram.

As seis espécies que apresentaram maior valor para o índice de regeneração natural na avaliação 1 foram: Vernonia polyanthes, Nectandra nitidula, Celtis iguanaea, Acrocomia aculeata, Piper aduncum e Copaifera langsdorffii. Destas, três são pioneiras, duas clímax exigente de luz e uma clímax tolerante à sombra. Na avaliação 2, a espécie Acrocomia aculeata foi substituída pela espécie Cedrela fissilis, situandose entre as espécies que se destacaram diante desse parâmetro. A copaíba (Copaifera langsdorffii) é uma espécie de grande plasticidade ecológica ocorrendo em vários biomas em diferentes fitofisionomias. Neste estudo, a copaíba também surgiu como uma das principais colonizadoras na nascente 2, apesar de pertencer ao grupo das clímax tolerante à sombra.

Para a nascente 2, na segunda avaliação, pôde-se verificar o mesmo que ocorreu na nascente $1 \mathrm{com}$ relação às diferenças de classificação proporcionadas pelos parâmetros $\mathrm{VI}$ e $\mathrm{RN}$, sendo que se analisarmos a importância de cada espécie pelo seu VI, constatamos que a espécie de maior importância na regeneração é Vernonia polyanthes, ao contrário do que ocorre com o parâmetro RN, em que a espécie Nectandra nitidula foi superior a espécie anterior.

As espécies Vernonia polyanthes, Nectandra nitidula, Celtis iguanaea, Acrocomia aculeata, Solanum lycocarpum e Copaifera langsdorffii se destacaram em relação ao valor de cobertura (VC) na primeira e segunda avaliação.

TABELA 4: Resumo da análise fitossociológica para a nascente 2, avaliação 1 e 2, apresentando a frequência relativa $(\mathrm{FR} \%)$, a densidade relativa $(\mathrm{DR} \%)$, a dominância relativa $(\mathrm{DoR} \%)$, o valor de importância (VI\%), o valor de cobertura (VC\%), a classe de tamanho relativa da regeneração natural (CTRRN\%) e o índice de regeneração natural (RN\%).

TABLE 4: Summary of fitossociologic analysis to spring 2, first and second evaluation, presenting the relative frequency $(\mathrm{FR} \%)$, relative density $(\mathrm{DR} \%)$, relative dominance $(\mathrm{DoR} \%)$, importance value (VI\%), cover value ( $\mathrm{VC} \%)$, relative class of size of the natural regeneration (CTRRN\%) and natural regeneration index (RN\%).

\begin{tabular}{l|c|c|c|c|c|c|c}
\hline \multicolumn{7}{c}{$1^{\mathbf{a}}$ avaliação } \\
\hline Espécie & FR & DR & DoR & VI & VC & CTRRN & RN \\
\hline Vernonia polyanthes & 10,00 & 11,65 & 15,66 & 37,32 & 27,32 & 9,66 & 10,44 \\
Nectandra nitidula & 4,62 & 12,78 & 14,28 & 31,68 & 27,06 & 11,45 & 9,62 \\
Celtis iguanaea & 6,92 & 7,14 & 11,43 & 25,49 & 18,57 & 5,67 & 6,58 \\
Acrocomia aculeata & 5,38 & 4,51 & 9,64 & 19,54 & 14,16 & 4,73 & 4,88 \\
Piper aduncum & 4,62 & 4,14 & 0,80 & 9,55 & 4,94 & 4,48 & 4,41 \\
Copaifera langsdorffii & 2,31 & 5,26 & 3,01 & 10,59 & 8,28 & 5,59 & 4,39 \\
Myrcia velutina & 2,31 & 4,14 & 2,01 & 8,45 & 6,14 & 4,94 & 3,80 \\
Ocotea pulchella & 2,31 & 3,76 & 0,68 & 6,75 & 4,44 & 4,88 & 3,65 \\
Solanum lycocarpum & 3,85 & 3,38 & 7,52 & 14,75 & 10,90 & 3,67 & 3,63 \\
Vernonia ferruginea & 3,85 & 3,01 & 2,61 & 9,47 & 5,62 & 3,16 & 3,34 \\
Lithraea molleoides & 4,62 & 2,26 & 1,34 & 8,21 & 3,60 & 2,83 & 3,23 \\
Baccharis dracunculifolia & 3,08 & 3,38 & 1,45 & 7,91 & 4,84 & 2,97 & 3,14 \\
\hline
\end{tabular}


TABELA 2: Continuação...

TABLE 2: Continuation...

\begin{tabular}{|c|c|c|c|c|c|c|c|}
\hline \multicolumn{8}{|c|}{$1^{\mathrm{a}}$ avaliação } \\
\hline Espécie & FR & DR & DoR & VI & $\mathrm{VC}$ & CTRRN & $\mathrm{RN}$ \\
\hline Cedrela fissilis & 3,08 & 2,26 & 1,93 & 7,26 & 4,18 & 2,62 & 2,65 \\
\hline Chrysophyllum marginatum & 1,54 & 2,63 & 0,57 & 4,74 & 3,20 & 3,58 & 2,58 \\
\hline Machaerium nictitans & 3,08 & 1,88 & 0,79 & 5,75 & 2,67 & 2,32 & 2,43 \\
\hline Machaerium hirtum & 3,08 & 1,88 & 0,57 & 5,53 & 2,45 & 2,11 & 2,36 \\
\hline Eugenia florida & 2,31 & 2,26 & 0,17 & 4,73 & 2,42 & 1,74 & 2,10 \\
\hline Solanum pseudochina & 2,31 & 1,50 & 0,31 & 4,13 & 1,82 & 2,04 & 1,95 \\
\hline Persea pyrifolia & 1,54 & 1,88 & 0,13 & 3,54 & 2,01 & 2,11 & 1,84 \\
\hline Rollinia laurifolia & 1,54 & 1,88 & 6,69 & 10,10 & 8,57 & 1,86 & 1,76 \\
\hline Acácia polyphylla & 2,31 & 1,13 & 0,17 & 3,61 & 1,30 & 1,30 & 1,58 \\
\hline Solanum granuloso-leprosum & 2,31 & 1,88 & 0,10 & 4,28 & 1,98 & 0,35 & 1,51 \\
\hline Psidium guajava & 2,31 & 1,13 & 0,05 & 3,49 & 1,18 & 1,09 & 1,51 \\
\hline Casearia decandra & 1,54 & 1,50 & 2,07 & 5,11 & 3,57 & 1,35 & 1,46 \\
\hline Myrcia tomentosa & 1,54 & 0,75 & 0,11 & 2,40 & 0,86 & 1,02 & 1,10 \\
\hline Randia nitida & 1,54 & 0,75 & 0,11 & 2,40 & 0,86 & 1,02 & 1,10 \\
\hline Colubrina sp. & 0,77 & 1,13 & 2,52 & 4,42 & 3,65 & 1,09 & 0,99 \\
\hline Sesbania sesban & 0,77 & 1,13 & 2,44 & 4,34 & 3,57 & 0,86 & 0,92 \\
\hline Nectandra lanceolata & 0,77 & 0,75 & 0,20 & 1,72 & 0,95 & 1,02 & 0,85 \\
\hline Solanum paniculatum & 0,77 & 0,75 & 0,35 & 1,87 & 1,10 & 1,02 & 0,85 \\
\hline Zanthoxylum rhoifolium & 0,77 & 0,75 & 1,10 & 2,62 & 1,85 & 0,79 & 0,77 \\
\hline Senna macranthera & 0,77 & 0,75 & 1,23 & 2,75 & 1,98 & 0,58 & 0,70 \\
\hline Myrsine umbellata & 0,77 & 0,75 & 0,86 & 2,38 & 1,61 & 0,56 & 0,69 \\
\hline Lonchocarpus guillemineanus & 0,77 & 0,38 & 0,15 & 1,29 & 0,52 & 0,51 & 0,55 \\
\hline Machaerium stipitatum & 0,77 & 0,38 & 0,05 & 1,20 & 0,43 & 0,51 & 0,55 \\
\hline Mangifera indica & 0,77 & 0,38 & 0,01 & 1,15 & 0,39 & 0,51 & 0,55 \\
\hline Miconia albicans & 0,77 & 0,38 & 0,01 & 1,15 & 0,39 & 0,51 & 0,55 \\
\hline Myrciaria cauliflora & 0,77 & 0,38 & 0,02 & 1,17 & 0,40 & 0,51 & 0,55 \\
\hline Solanum cernuum & 0,77 & 0,38 & 0,01 & 1,16 & 0,39 & 0,51 & 0,55 \\
\hline Tapirira obtusa & 0,77 & 0,38 & 0,07 & 1,22 & 0,45 & 0,51 & 0,55 \\
\hline Xylopia brasiliensis & 0,77 & 0,38 & 0,21 & 1,36 & 0,59 & 0,51 & 0,55 \\
\hline Casearia lasiophylla & 0,77 & 0,38 & 2,27 & 3,41 & 2,64 & 0,28 & 0,47 \\
\hline Eriobotrya japonica & 0,77 & 0,38 & 0,48 & 1,63 & 0,86 & 0,28 & 0,47 \\
\hline Gochnatia polymorpha & 0,77 & 0,38 & 0,29 & 1,44 & 0,67 & 0,28 & 0,47 \\
\hline Miconia sp. & 0,77 & 0,38 & 0,60 & 1,74 & 0,97 & 0,28 & 0,47 \\
\hline Rollinia sericea & 0,77 & 0,38 & 1,08 & 2,23 & 1,46 & 0,28 & 0,47 \\
\hline Cecropia pachystachya & 0,77 & 0,38 & 1,85 & 2,99 & 2,23 & 0,07 & 0,40 \\
\hline Total & 100,00 & 100,00 & 100,00 & 300,00 & 200,00 & 100,00 & 100,00 \\
\hline \multicolumn{8}{|c|}{$2^{\mathrm{a}}$ avaliação } \\
\hline Espécie & FR & DR & DoR & VI & $\mathrm{VC}$ & CTRRN & $\mathrm{RN}$ \\
\hline Nectandra nitidula & 5,48 & 15,26 & 9,22 & 29,96 & 24,48 & 16,22 & 12,32 \\
\hline Vernonia polyanthes & 8,22 & 8,77 & 18,88 & 35,87 & 27,65 & 5,25 & 7,41 \\
\hline Celtis iguanaea & 6,16 & 5,84 & 16,22 & 28,23 & 22,07 & 4,91 & 5,64 \\
\hline Piper aduncum & 5,48 & 4,87 & 1,12 & 11,47 & 5,99 & 5,14 & 5,16 \\
\hline Copaifera langsdorffii & 2,05 & 5,19 & 2,41 & 9,66 & 7,61 & 6,33 & 4,53 \\
\hline Cedrela fissilis & 4,11 & 4,55 & 2,37 & 11,03 & 6,92 & 4,29 & 4,31 \\
\hline Machaerium nictitans & 4,79 & 3,25 & 1,17 & 9,21 & 4,42 & 4,08 & 4,04 \\
\hline
\end{tabular}


TABELA 2: Continuação...

TABLE 2: Continuation...

\begin{tabular}{|c|c|c|c|c|c|c|c|}
\hline \multicolumn{8}{|c|}{$2^{\mathrm{a}}$ avaliação } \\
\hline Espécie & FR & DR & DoR & VI & $\mathrm{VC}$ & CTRRN & $\mathrm{RN}$ \\
\hline Acrocomia aculeata & 4,79 & 3,25 & 7,50 & 15,54 & 10,74 & 2,61 & 3,55 \\
\hline Vernonia ferruginea & 3,42 & 3,57 & 2,38 & 9,37 & 5,95 & 3,10 & 3,37 \\
\hline Psidium guajava & 3,42 & 2,60 & 0,31 & 6,33 & 2,90 & 3,23 & 3,08 \\
\hline Lithraea molleoides & 4,11 & 2,27 & 1,46 & 7,85 & 3,74 & 2,39 & 2,93 \\
\hline Ocotea pulchella & 2,05 & 2,92 & 0,37 & 5,35 & 3,29 & 3,62 & 2,87 \\
\hline Myrcia velutina & 2,05 & 2,60 & 1,68 & 6,33 & 4,28 & 3,09 & 2,58 \\
\hline Eugenia florida & 2,05 & 2,60 & 0,26 & 4,91 & 2,85 & 2,99 & 2,55 \\
\hline Chrysophyllum marginatum & 1,37 & 2,60 & 0,66 & 4,63 & 3,26 & 3,23 & 2,40 \\
\hline Solanum lycocarpum & 2,74 & 2,27 & 6,22 & 11,23 & 8,49 & 1,90 & 2,31 \\
\hline Baccharis dracunculifolia & 2,74 & 2,27 & 1,85 & 6,86 & 4,12 & 1,59 & 2,20 \\
\hline Acácia polyphylla & 2,05 & 1,95 & 0,34 & 4,34 & 2,29 & 2,43 & 2,14 \\
\hline Machaerium hirtum & 3,42 & 1,62 & 1,37 & 6,42 & 3,00 & 1,37 & 2,14 \\
\hline Solanum pseudochina & 2,05 & 1,62 & 0,28 & 3,96 & 1,90 & 1,72 & 1,80 \\
\hline Casearia decandra & 1,37 & 1,95 & 1,56 & 4,88 & 3,51 & 1,52 & 1,61 \\
\hline Persea pyrifolia & 1,37 & 1,30 & 0,09 & 2,76 & 1,39 & 1,41 & 1,36 \\
\hline Machaerium stipitatum & 1,37 & 0,97 & 0,15 & 2,49 & 1,12 & 1,37 & 1,24 \\
\hline Solanum granuloso-leprosum & 1,37 & 0,97 & 0,15 & 2,50 & 1,13 & 1,37 & 1,24 \\
\hline Rollinia laurifolia & 1,37 & 1,30 & 3,95 & 6,62 & 5,25 & 0,95 & 1,21 \\
\hline Myrciaria cauliflora & 0,68 & 0,97 & 0,15 & 1,80 & 1,12 & 1,37 & 1,01 \\
\hline Myrcia tomentosa & 1,37 & 0,65 & 0,11 & 2,13 & 0,76 & 0,91 & 0,98 \\
\hline Randia nitida & 1,37 & 0,65 & 0,10 & 2,12 & 0,75 & 0,91 & 0,98 \\
\hline Nectandra lanceolata & 0,68 & 0,97 & 0,22 & 1,88 & 1,19 & 1,12 & 0,93 \\
\hline Gochnatia polymorpha & 1,37 & 0,65 & 0,46 & 2,47 & 1,10 & 0,67 & 0,90 \\
\hline Sesbania sesban & 1,37 & 0,65 & 0,24 & 2,26 & 0,89 & 0,67 & 0,90 \\
\hline Solanum paniculatum & 0,68 & 0,97 & 0,56 & 2,22 & 1,54 & 0,64 & 0,76 \\
\hline Casearia silvestre & 0,68 & 0,65 & 0,08 & 1,42 & 0,73 & 0,91 & 0,75 \\
\hline Psychotria sessilis & 0,68 & 0,65 & 0,03 & 1,36 & 0,68 & 0,91 & 0,75 \\
\hline Colubrina sp. & 0,68 & 0,65 & 2,13 & 3,46 & 2,78 & 0,60 & 0,64 \\
\hline Senna macranthera & 0,68 & 0,65 & 1,17 & 2,50 & 1,82 & 0,60 & 0,64 \\
\hline Zanthoxylum rhoifolium & 0,68 & 0,65 & 0,79 & 2,13 & 1,44 & 0,60 & 0,64 \\
\hline Myrsine umbellata & 0,68 & 0,65 & 0,56 & 1,89 & 1,21 & 0,29 & 0,54 \\
\hline Lonchocarpus guillemineanus & 0,68 & 0,32 & 0,18 & 1,19 & 0,50 & 0,46 & 0,49 \\
\hline Mangifera indica & 0,68 & 0,32 & 0,04 & 1,05 & 0,36 & 0,46 & 0,49 \\
\hline Miconia albicans & 0,68 & 0,32 & 0,01 & 1,02 & 0,34 & 0,46 & 0,49 \\
\hline Tapirira guianensis & 0,68 & 0,32 & 0,01 & 1,02 & 0,33 & 0,46 & 0,49 \\
\hline Tapirira obtusa & 0,68 & 0,32 & 0,07 & 1,08 & 0,40 & 0,46 & 0,49 \\
\hline Xylopia brasiliensis & 0,68 & 0,32 & 0,16 & 1,17 & 0,49 & 0,46 & 0,49 \\
\hline Eriobotrya japonica & 0,68 & 0,32 & 0,42 & 1,43 & 0,74 & 0,21 & 0,41 \\
\hline Casearia lasiophylla & 0,68 & 0,32 & 1,67 & 2,68 & 1,99 & 0,14 & 0,38 \\
\hline Cecropia pachystachya & 0,68 & 0,32 & 1,02 & 2,03 & 1,35 & 0,14 & 0,38 \\
\hline Maclura tinctoria & 0,68 & 0,32 & 5,32 & 6,33 & 5,65 & 0,14 & 0,38 \\
\hline Miconia sp. & 0,68 & 0,32 & 0,41 & 1,42 & 0,73 & 0,14 & 0,38 \\
\hline Rollinia sericea & 0,68 & 0,32 & 2,11 & 3,12 & 2,43 & 0,14 & 0,38 \\
\hline Myrcia fallax & 0,68 & 0,32 & 0,01 & 1,02 & 0,33 & 0,04 & 0,35 \\
\hline Total & 100,00 & 100,00 & 100,00 & 300,00 & 200,00 & 100,00 & 100,00 \\
\hline
\end{tabular}

Na Figura 6, ( $\mathrm{a}$ e b) são apresentadas as densidades absolutas por classe de tamanho das seis espécies 
com maior índice de regeneração natural na primeira e segunda avaliação respectivamente. Verifica-se que somente as espécies Nectandra nitidula (avaliação 1 e 2), Celtis iguanaea (avaliação 1) e Copaifera langsdorffii (avaliação 1 e 2) apresentaram indivíduos em todas as classes de tamanho.
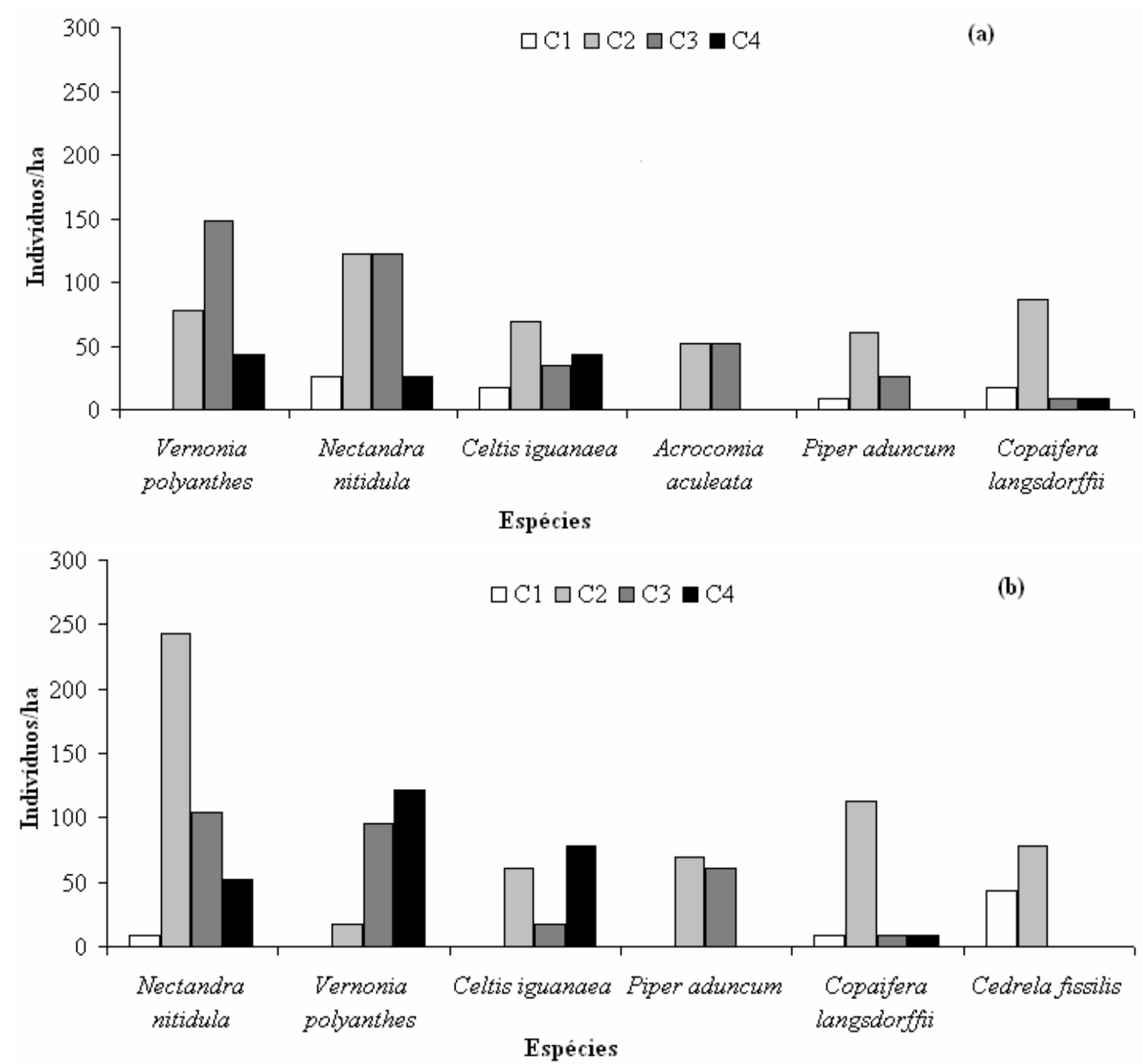

FIGURA 6: Distribuição da densidade por classe de tamanho da regeneração natural, para as seis espécies de maior RN, registradas na nascente 2, na primeira (a) e segunda (b) avaliação (C1: plantas com altura menor que $0,3 \mathrm{~m}$; $\mathrm{C} 2$ : plantas com altura entre 0,3 e 1,5 m, C3: plantas com altura maior que $1,5 \mathrm{~m}$ e menor que 3,0 e C4: plantas com altura maior ou igual a $3,0 \mathrm{~m}$ e com DAP menor que $5 \mathrm{~cm}$ ).

FIGURE 6: Distribution of density per class of size of natural regeneration, for the six species of larger RN, registered in spring 2 , in first (a) and second (b) evaluation $(\mathrm{C} 1$ : plants with height smaller than $0.3 \mathrm{~m}$; C2: plants with height between 0.3 and $1.5 \mathrm{~m}$; C3: plants with height larger than $1.5 \mathrm{~m}$ and smaller than $3.0 \mathrm{~m}$ and $\mathrm{C} 4$ : plants with height larger or equal to $3.0 \mathrm{~m}$ and with DAP smaller than $5 \mathrm{~cm}$ ).

A espécie Vernonia polyanthes apresentou indivíduos distribuídos nas classes de tamanho 2, 3 e 4. Como mencionado anteriormente Copaifera langsdorffii possui indivíduos nas classes de tamanho 1, 2, 3 e 4, assim como a espécie Nectandra nitidula. Já os indivíduos da espécie Celtis iguanaea estão distribuídos nas classes de tamanho 1, 2, 3 e 4 (primeira avaliação) e 2, 3 e 4 (segunda avaliação). Acrocomia aculeata possui indivíduos nas classes de tamanho 2 e 3, enquanto a espécie Cedrela fissilis tem seus indivíduos distribuídos nas classes 1 e 2. Finalmente, a espécie Piper aduncum de indivíduos na classe 1 pode apresenta indivíduos nas classes de tamanho 1, 2 e 3 (avaliação 1) e 2 e 3 (avaliação 2). A ausência indicar dificuldades de regeneração relacionadas à competição com Brachiaria sp. ou mesmo o sombreamento proporcionado pelo crescimento da vegetação. 
$\mathrm{Na}$ avaliação 1 , a classe 1 é composta por $7,52 \%$ do total de indivíduos amostrados, enquanto as classes 2, 3 e 4 possuem 55,26, 30,08 e 7,14\% respectivamente. Com relação à avaliação 2, verifica-se que a classe $2(53,9 \%)$ apresenta a maior porcentagem do total de indivíduos, seguida pelas classes $3(25 \%), 4$ $(16,88 \%)$ e $1(4,22 \%)$. Observa-se que houve aumento da densidade na classe 4 e redução na classe 1 indicando o crescimento dos indivíduos na área.

\section{Diversidade florística}

Na Tabela 5, são apresentados os números de indivíduos e espécies, e o índice de diversidade de Shannon (H') e equabilidade de Pielou (J') registrados para as nascentes 1 e 2, na primeira e segunda avaliação.

O maior índice de diversidade $(3,384)$ foi registrado para a nascente 2 na segunda avaliação realizada. Esse valor se encontra superior aos valores encontrados por Alvarenga (2004) e Vilela (2006), em trabalhos realizados com nascentes da mesma região do presente estudo. O índice de equabilidade também foi maior na nascente 2 , nas duas avaliações, indicando maior uniformidade de distribuição das espécies.

TABELA 5: Dados estruturais e de diversidade de espécies referentes ao levantamento fitossociológico da regeneração natural, para a nascente 1 e para a nascente 2 , na primeira e segunda avaliação. $\left(\mathrm{N}=\right.$ número de indivíduos; $\mathrm{NE}=$ número de espécies; $\mathrm{H}^{\prime}$ = índice de diversidade de Shannon e J' = índice de equabilidade de Pielou).

TABLE 5: Structural and diversity data of species concerning the fitossociologic survey of natural regeneration, to springs 1 and 2 , in first and second evaluation. $(\mathrm{N}=$ individuals number; $\mathrm{NE}=$ species number; $\mathrm{H}^{\prime}=$ Shannon diversity index and $\mathrm{J}^{\prime}=$ Pielou uniformity index).

\begin{tabular}{l|c|c|c|c}
\hline \multirow{2}{*}{ Parâmetros } & \multicolumn{2}{|c|}{ Nascente 1 } & \multicolumn{2}{c}{ Nascente 2 } \\
\cline { 2 - 5 } & Avaliação 1 & Avaliação 2 & Avaliação 1 & Avaliação 2 \\
\hline N & 162 & 216 & 266 & 308 \\
NE & 13 & 13 & 47 & 51 \\
H' & 1,582 & 1,557 & 3,324 & 3,384 \\
J' & 0,617 & 0,607 & 0,863 & 0,861 \\
\hline
\end{tabular}

Os baixos valores de diversidade encontrados na nascente 1 podem estar associados ao fato de que poucas espécies são responsáveis pela grande maioria dos indivíduos amostrados nesta área, sendo que apenas as espécies Baccharis dracunculifolia e Vernonia ferruginea apresentam juntas 71,61 e 72,68\% do número total de indivíduos amostrados na primeira e segunda avaliação respectivamente.

Outro fator que pode ter contribuído para que a nascente 2 apresente maiores valores de diversidade que a nascente 1, reside no fato de que no entorno da nascente 2 se encontra um pequeno fragmento o qual pode fornecer propágulos para a dispersão das espécies encontradas nesta área. Já em relação à nascente 1 não é verificada a presença de nenhum fragmento próximo a esta.

\section{Similaridade florística entre as duas nascentes avaliadas}

Ao se comparar a similaridade florística existente entre as duas nascentes pelo índice de Jaccard, verifica-se que o valor de tal índice é de 20,0 e 18,5\% para as avaliações 1 e 2 respectivamente.

Esses baixos valores podem ser explicados em razão da presença de um pequeno fragmento localizado no entorno da nascente 2 funcionando como fonte de propágulos à dispersão de diversas espécies registradas nessa área, ao passo que próximo à nascente 1 , encontram-se apenas alguns povoamentos antigos de Eucalyptus sp. e Pinus sp. Outro ponto importante, já mencionado, se refere ao fato da área da nascente 1 apresentar uma maior ocupação por capim Brachiaria sp. se comparada à nascente 2, o qual exerce forte competição à regeneração de várias espécies.

\section{Dinâmica da regeneração natural}

Na Tabela 6, são apresentados os resultados para os cálculos de dinâmica da regeneração natural dos indivíduos registrados nas nascentes 1 e 2, contabilizados para a amostra total de espécies que apresentaram indivíduos tanto no primeiro como no segundo inventário. 
TABELA 6: Dinâmica da regeneração natural dos indivíduos registrados nas nascentes 1 e 2 expressa em número de indivíduos e área basal, contabilizada para a amostra total.

TABLE 6: Natural regeneration dynamic of the individuals registered in springs 1 and 2 expressed in individuals number and basal area, considered for the total sample.

\begin{tabular}{|c|c|c|}
\hline Parâmetros & Nascente 1 & Nascente 2 \\
\hline Número de indivíduos inicial & 162 & 266 \\
\hline Número de indivíduos final & 216 & 302 \\
\hline Sobreviventes & 149 & 229 \\
\hline Mortos & 13 & 37 \\
\hline Recrutados & 67 & 73 \\
\hline Taxa de mortalidade $\left(\%\right.$ ano $\left.^{-1}\right)$ & 15,4 & 25,9 \\
\hline Taxa de recrutamento $\left(\%\right.$ ano $\left.^{-1}\right)$ & 52,4 & 42,5 \\
\hline Taxa de rotatividade $\left(\%\right.$ ano $\left.^{-1}\right)$ & 33,9 & 34,2 \\
\hline Taxa de mudança $\left(\%\right.$ ano $\left.^{-1}\right)$ & 77,8 & 28,9 \\
\hline Área basal inicial $\left(\mathrm{m}^{2}\right)$ & 0,052097 & 0,184157 \\
\hline Área basal final $\left(\mathrm{m}^{2}\right)$ & 0,100400 & 0,234858 \\
\hline Área basal mortas $\left(\mathrm{m}^{2}\right)$ & 0,002191 & 0,007995 \\
\hline Decremento dos sobreviventes $\left(\mathrm{m}^{2}\right)$ & $-0,000253$ & $-0,004727$ \\
\hline Recrutas $\left(\mathrm{m}^{2}\right)$ & 0,007328 & 0,015955 \\
\hline Incremento dos sobreviventes $\left(\mathrm{m}^{2}\right)$ & 0,043419 & 0,047469 \\
\hline Taxa de perdas $\left(\%\right.$ ano $\left.^{-1}\right)$ & 9,2 & 13,3 \\
\hline Taxa de ganhos $\left(\%\right.$ ano $\left.^{-1}\right)$ & 75,5 & 46,7 \\
\hline Taxa de rotatividade $\left(\%\right.$ ano $\left.^{-1}\right)$ & 42,4 & 30,0 \\
\hline Taxa de mudança $\left(\%\right.$ ano $\left.^{-1}\right)$ & 271,4 & 62,6 \\
\hline
\end{tabular}

Com relação aos parâmetros de dinâmica expressos em densidade populacional, observou-se que a nascente 1 , quando comparada com a nascente 2, apresentou maiores valores para os parâmetros taxa de recrutamento $\left(52,4 \%\right.$ ano $\left.^{-1}\right)$ e taxa de mudança $\left(77,8 \% \mathrm{ano}^{-1}\right)$, ao passo que a nascente 2 obteve maiores valores associados às taxas de mortalidade $\left(25,9 \% \mathrm{ano}^{-1}\right)$ e rotatividade $\left(34,2 \%\right.$ ano $\left.^{-1}\right)$.

Já com relação à dinâmica da regeneração natural expressa em área basal, observou-se que a nascente 1 obteve os maiores valores de taxa de ganhos $\left(75,5 \%\right.$ ano $\left.^{-1}\right)$, taxa de rotatividade $\left(42,4 \%\right.$ ano $\left.^{-1}\right)$ e taxa de mudança $\left(271,4 \%\right.$ ano $\left.^{-1}\right)$, quando comparada com a nascente 2 . Por outro lado, a nascente 2 apresentou maior valor para a taxa de perdas $\left(13,3 \% \mathrm{ano}^{-1}\right)$.

Os resultados obtidos mostraram que, durante o período de tempo avaliado, houve um aumento líquido tanto para a densidade populacional quanto para a área basal dos indivíduos amostrados em ambas as nascentes, como resultado das taxas de recrutamento superiores às de mortalidade e das taxas de ganho superiores às taxas de perdas.

Esses resultados indicam que ambas as nascentes se apresentam em estágio de recuperação, sendo que a nascente 2 parece se encontrar em um estágio mais avançado quando comparada à nascente 1 . Por último, pode-se observar que o cercamento das nascentes contribuiu sobremaneira para o processo de recuperação das áreas, mesmo em se tratando de um curto período de tempo para avaliação.

\section{CONCLUSÕES}

Diante dos resultados obtidos neste trabalho, pode-se concluir que:

O solo no entorno das duas nascentes apresentou resistência à penetração de moderada a alta até 40 $\mathrm{cm}$ de profundidade.

A umidade do solo no entorno das nascentes variou de 15 a $36 \%$ na nascente 1 e de 32 a $46 \%$ na nascente 2, apresentando variabilidade espacial dependente da época do ano, com os maiores valores nas áreas mais próximas ao ponto de vazão.

As espécies comuns às duas nascentes estudadas foram: Baccharis dracunculifolia, Celtis iguanaea, Gochnatia polymorpha, Lithraea molleoides, Machaerium nictitans, Piper aduncum, Solanum lycocarpum, 
Solanum pseudoquina, Vernonia ferruginea e Vernonia polyanthes.

As espécies Baccharis dracunculifolia, Lithraea molleoides, Solanum lycocarpum, Vernonia ferruginea e Vernonia polyanthes se destacaram em relação ao parâmetro regeneração natural para a nascente 1.

As espécies que se destacaram por apresentar maiores valores do índice regeneração natural na nascente 2 foram: Acrocomia aculeata, Celtis iguanaea, Copaifera langsdorffii, Nectandra nitidula, Piper aduncum e Vernonia polyanthes.

O maior índice de diversidade foi encontrado na nascente 2 , na segunda avaliação, com valor de 3,384, em razão da presença de fragmento de mata nativa na área.

O índice de similaridade florística entre as duas nascentes, apesar de sua proximidade, foi baixo, em razão sobretudo do pequeno número de espécies presentes na nascente 1.

Durante o período de monitoramento, verificou-se um aumento significativo de 33,33 e 15,8\% no número de indivíduos amostrados nas nascentes 1 e 2 respectivamente;

A proximidade do fragmento mostrou-se importante na ocorrência de maior diversidade de espécies na regeneração natural.

A recuperação da vegetação das duas nascentes estudadas, pelo método da regeneração natural, apresenta grande potencial, sendo necessária, porém, a adoção de técnicas que possibilitem o controle do capim Brachiaria sp.

\section{REFERÊNCIAS BIBLIOGRÁFICAS}

ALVARENGA, A. P. Avaliação inicial da recuperação de mata ciliar em nascentes. 2004. 175 p. Dissertação (Mestrado em Engenharia Florestal) - Universidade Federal de Lavras, Lavras.

APG. An update of the Angiosperm Phylogeny Group classification for the orders and families of flowering plants: APG II. Botanical Journal of the Linnean Society, v. 141, p. 399-436, Apr. 2003.

ARSHAD, M. A.; LOWERY, B.; GROSSMAN, B. Physical tests for monitoring soil quality. In: DORAN, J.W.; JONES, A.J. Methods for assessing soil quality. Madison: Soil Science Society of America, 1996. p.123-141.

BOTELHO, S. A.; DAVIDE, A. C. Métodos silviculturais para recuperação de nascentes e recomposição de matas ciliares. In: SIMPÓSIO NACIONAL SOBRE RECUPERAÇÃO DE ÁREAS DEGRADADAS, 5., 2002, Belo Horizonte. Anais... Belo Horizonte: 2002. p. 123-145.

BRASIL, Ministério da agricultura e reforma agrária. Normais climatológicas 1961-1990. Brasília: MARA, 1992. $84 \mathrm{p}$.

BROWER, J. E.; ZAR, J. H. Field and laboratory methods for general ecology. Dubuque: W. M. C. Brow, 1984. $226 \mathrm{p}$.

CALEGARIO, N. et al. Parâmetros florísticos e fitossociológicos da regeneração natural de espécies arbóreas nativas no sub-bosque de povoamentos de Eucaliptos. Revista Árvore, Viçosa, v. 17, n. 1, p. 19-29, jan./abr. 1993.

CARVALHO, P. E. R. Técnicas de recuperação e manejo de áreas degradadas. In: GALVÃO, A. P. M. Reflorestamento de propriedades rurais para fins produtivos e ambientais: Um guia para ações municipais e regionais. Brasília: Embrapa Florestas, 2000. cap. 14. p. 251-268.

COSTA, S. S. B. Estudo da Bacia do Ribeirão Jaguará - MG, como base para o planejamento da conservação e recuperação das nascentes e matas ciliares. 2004. 214 p. Dissertação (Mestrado em Engenharia Florestal) Universidade Federal de Lavras, Lavras.

DAVIDE, A. C.; BOTELHO, S. A. Análise crítica dos programas de reposição de Matas Ciliares em Minas Gerais. In: SIMPÓSIO MATA CILIAR: Ciência e Tecnologia, 1999, Belo Horizonte. Anais... Belo Horizonte:1999. p.172-188.

EMBRAPA, Empresa Brasileira de Pesquisa Agropecuária. Serviço Nacional de Levantamento e Conservação de Solos: manual de métodos de análise de solo. Rio de Janeiro: EMBRAPA/SNLCS, 1979. 247 p.

FINOL, U. H. Nuevos parâmetros a considerarse em el analisis estrutural de lãs selvas virgnes tropicales. Revista Forestal Venezolana, Mérida, v. 14, n. 21, p. 337-1144, 1971.

GARDNER, W. H. Water content. In: KLUTE, A. Methods of soil analysis. Madison: Wi ASA, CSSA e SSSA, 1986. p.493-594.

HIGUCHI, P. Dinâmica da regeneração natural da vegetação arbórea em um fragmento de floresta estacioanal semidecidual Montana secundária, em Viçosa, MG. 2003. 107 p. Dissertação (Mestrado em Engenharia Florestal) Universidade Federal de Viçosa, Viçosa. 
IBGE. Instituto Brasileiro de Geografia e Estatística. Recursos naturais e meio ambiente: uma visão do Brasil. 2. ed. Rio de Janeiro: DEDIT/CDDI, 1997. 208 p.

KORNING, J.; BALSLEV, H. Growth and mortality of trees in Amazonian tropical rain forest in Ecuador. Journal of Vegetation Science, Knivsta, v. 4, n. 1, p. 77-86, Jan./Feb. 1994.

LIMA, W. P. Função Hidrológica da Mata Ciliar. In: SIMPÓSIO SOBRE MATA CILIAR, 1989, Campinas. Anais... Campinas: Fundação Cargil, 1989. p. 25-42.

MELLO, J. M. de. Geoestatística aplicada ao inventário florestal. 2004. 110 f. Tese (Doutorado em Recursos Florestais) - Escola Superior de Agricultura Luiz de Queiroz, Universidade de São Paulo, Piracicaba.

OLIVEIRA-FILHO, A. T.; MELLO, J. M.; SCOLFORO, J. R. S. Effects of past disturbance and edges on tree community structure and dynamics within a fragment of tropical semideciduous forest in south-eastern Brazil over a five year period (1987-1992). Plant Ecology, Dordrecht, v. 131, n. 1, p. 45-66, Jan. 1997.

PEREIRA, I. M. et al. Regeneração natural em um remanescente de caatinga sob diferentes níveis de perturbação, no agreste Paraibano. Acta Botânica Brasílica, São Carlos, v. 15, n.3, p. 413-426, set./dez. 2001.

PINTO, L. V. A. Caracterização física da sub-bacia do Ribeirão Santa Cruz, Lavras, MG e propostas de recuperação de suas nascentes. 2003. 165 p. Dissertação (Mestrado em Engenharia Florestal) - Universidade Federal de Lavras, Lavras.

RIBEIRO JR, P. P.; DIGGLE, P. P. GeoR: a package for geostatistical analysis. R - News, Rochester, 2001. p.1518.

RODRIGUES, L. A. et al. Florística e estrutura da comunidade arbórea de um fragmento florestal em Luminárias, MG. Acta Botânica Brasílica, São Carlos, v. 17, n. 1, p. 71-87, jan./jun. 2003.

SCOLFORO, J. R. S. Inventário Florestal. Lavras: Universidade Federal de Lavras, 2004. 440 p.

SHEIL, D.; BURSLEM, D. F. R. P.; ALDER, D. The interpretation and misinterpretation of mortality rate measures. Journal of Ecology, Oxford. v. 83, n. 2, p. 331-333, maio/ago. 1995.

SHEIL, D.; JENNINGS, S.; SAVILL, P. Long-term permanent plot observations of vegetation dynamics in Budongo, a Ugandan rain forest. Journal of Tropical Ecology, Cambridge, v. 16, n. 1, p. 765-800, Jan./Feb. 2000.

SOIL SURVEY STAFF. Soil survey manual. Washingtons: USDASCS, U.S., 1993. 437 p.

SOUZA, Z. M.; MARQUES JÚNIOR, J.; PERREIRA, G. T. Variabilidade espacial da estabilidade de agregados e matéria orgânica em solos de relevos diferentes. Pesquisa Agropecuária Brasileira, v. 39, n. 5, p. 491-499, maio 2004a.

SOUZA, Z. M. et al. Variabilidade espacial da textura de um latossolo vermelho eutroférrico sob cultivo de cana-deaçúcar. Engenharia Agrícola, Sorocaba, v. 24, n. 2, p. 309-319, maio/ago. 2004b.

SOUZA, Z. M.et al. Variabilidade espacial de atributos físicos em $\mathrm{m}$ Latossolo Vermelho Distrófico sob semeadura direta em Selvíria (MS). Revista Brasileira de Ciência do Solo, v. 25, p. 669-707, 2001.

STOLF, R.; FERNANDES, J.; FURLANI NETO, V. L. Recomendação para o uso do penetrômetro de impacto: modelo IAA/PLANALSUCAR/STOLF. 1983. 9 p. (Série Penetrômetro de Impacto. Boletim Técnico, 1).

STOLF, R. Teoria e tese experimental de fórmulas de transformação dos dados de penetrômetro de impacto em resistência do solo. Revista Brasileira de Ciência do Solo, Campinas, v. 15, n. 3, p.229-235, maio/jun. 1991.

WERNECK, M.; FRANCESCHINELLI, E. V. Dynamics of a dry forest fragment after the exclusion of human disturbance in southeastern Brazil. Plant Ecology, Dordrecht, v. 174, n. 2, p. 337-346, Feb. 2004.

VILELA, D.F. Estratégias para a recuperação da vegetação no entorno de nascentes. 2006 . 71 p. Dissertação (Mestrado em Engenharia Florestal) - Universidade Federal de Lavras, Lavras. 